Research Article

\title{
Seismic Performance and Failure Mechanism of Megabraced Frame-Core Tube Structures with Different Brace Patterns
}

\author{
Zuohua Li $\mathbb{D}^{1},{ }^{1}$ Pengyuan Liu $\mathbb{D},{ }^{1}$ Jun Teng $\mathbb{D},{ }^{1}$ and Ying Wang $\mathbb{D}^{2}$ \\ ${ }^{1}$ School of Civil and Environment Engineering, Shenzhen Graduate School, Harbin Institute of Technology, \\ Shenzhen 518055, China \\ ${ }^{2}$ Department of Civil and Environmental Engineering, University of Surrey, Guildford GU2 7XH, UK
}

Correspondence should be addressed to Jun Teng; tengj@hit.edu.cn

Received 7 August 2018; Revised 8 October 2018; Accepted 10 October 2018; Published 25 October 2018

Academic Editor: Rosario Montuori

Copyright (c) 2018 Zuohua Li et al. This is an open access article distributed under the Creative Commons Attribution License, which permits unrestricted use, distribution, and reproduction in any medium, provided the original work is properly cited.

\begin{abstract}
The effect of mega braces on structural stiffness has been comprehensively discussed for various megabraced frame-core tube structures. However, few studies have considered how mega braces affect the failure mechanism of mega structures exposed to seismic action, which is a nonlinear process. To address this issue, we present a study on the effects of different brace patterns on the failure mechanism and seismic performance of megabraced frame-core tube structures. Specifically, the yield order of components, the distribution of plasticity, the distribution of internal forces, the degradation of structural nonlinear stiffness, and the behavior factor have been investigated. This study reveals that the yield of mega braces will change the deformation mode of adjacent mega columns and thus affect the plasticity distribution of adjacent substructures. The enhancement of mega braces improves the exterior tubes (thereby increasing their capacity to serve as the second line of seismic defence), mitigates the rate at which system stiffness degrades, and improves the overstrength of the structural systems. In addition, after the yield of mega braces, the maintenance of a higher-amplitude axial force changes the proportion of internal force components in mega columns, reducing their ductility and further affecting the overall ductility of the structural system.
\end{abstract}

\section{Introduction}

The megabraced frame-core tube structure has been widely used in super-high-rise buildings. Its mechanical behavior provides superior lateral capacity and allows considerable freedom in architectural planning of the interior space. Many super-tall buildings, including the 108-story CITIC Tower [1], the 118-story Ping'An Financial Center [2], and the 101-story Shanghai World Financial Center [3], were constructed using the megabraced frame-core tube system.

Megabraced frame-core tube system places mega columns at the corners of the building and arranges mega braces around the frame tube. Such an arrangement can provide higher shear resistance and transfer load from the inner column to the periphery [4]. The addition of mega braces transforms megaframe structures into megatruss structures [5]. In these megatruss structures, the axial stiffness of mega members provides most of the lateral stiffness instead of the bending stiffness of members. The structure of such a force form increases structural lateral stiffness significantly. The huge lateral stiffness reduces the structural stiffness requirements of internal conventional members, providing considerable freedom for the architectural planning of secondary structural space.

Previous research on the effects of mega braces in megaframe-braced structures generally focuses on the force characteristics of external tubes and overall deformation characteristics $[6,7]$. The different patterns of megabraces lead to differences in the internal forces of key components and in the overall stiffness distribution, which may affect the nonlinear development of the structure. A few studies focus on how megabraces affect the common frame tube structures. They show that the brace pattern affects not only the structural lateral stiffness and internal force distribution [8] but also the internal force distribution [9] and the distribution of plasticity in structural components, using the 
buckling-restrained brace (BRB) $[10,11]$. Indeed, both the different structural types of external tubes and the arrangement of the core tube will affect the structural nonlinear performance [12]. Therefore, research should concentrate on internal force transmission and nonlinear development process by considering the arrangement of both external tubes and core tube.

Most studies of the seismic performance of megabraced frame-core tube structures focus on mechanical characteristics, structural deformation characteristics [13], and the verification of the performance-control parameters under design seismic conditions [2, 14]. Some research has considered the differences in the energy dissipation distribution and the collapse capacity under the design seismic condition with various braced schemes $[1,15]$. These studies concluded that the chosen brace pattern affects the distribution of structural internal force and even changes the nonlinear development process of the structures. Generally, tall buildings are subjected to greater shear and bending moments under earthquakes than wind loads [16]. High-rise building structure design is usually controlled by seismic loads, especially in high-intensity earthquake areas such as China [17]. To ensure structural safety during the nonlinear development process under seismic action, research should concentrate on how brace patterns affect seismic performance and failure mechanisms in megabraced frame-core tube structures.

To address the above research gaps, this paper explores the structural failure mechanism using nonlinear static and dynamic analyses. It discusses the structural seismic performance in terms of the components yield order, the plasticity distribution, the internal forces distribution, and the nonlinear stiffness degradation. This allows us to explore the differences and characteristics of the seismic performance and the failure mechanism of megabraced frame-core tube structures with different brace patterns.

\section{Design of Analysis Model Structures}

In this study, we designed three prototype 50 -story $4 \times 4$-bay megabraced frame-core tube structures in accordance with the current Chinese Code for Seismic Design of Buildings [18] and the design of Tianjin 117 Tower [19]. The current Chinese Code design method classifies structural components according to the importance of components. For different seismic performance objectives, the requirements for the damage degree of various components are different. The primary beam and primary column are the key components in this structural system and require minimal damage under earthquake action in accordance with current Chinese Code. The primary beam and primary column with the large cross sections area have the high load-carrying capacity, which can better meet the design requirements of the Chinese Code. In this study, we label the three models as $5 \mathrm{MC}, 5 \mathrm{MBC}$, and 5MXBC. The megabraced frame-core tube structure with diagonal braces is labeled $5 \mathrm{MBC}$, and the megabraced frame-core tube structures without braces and with $\mathrm{X}$-braces are labeled $5 \mathrm{MC}$ and $5 \mathrm{MXBC}$, respectively (Figures 1 and 2). To facilitate the discussion, the part consisting of mega members, including mega beams, mega columns, and mega braces, in the exterior tube is called the "primary frame." The part consisting of conventional members in the exterior tube, including conventional beams and conventional columns, is called the "secondary frame." The secondary frames are mainly designed for gravity loads, which consist of a dead load of $2.5 \mathrm{kN} / \mathrm{m}^{2}$ and a live load of $2 \mathrm{kN} / \mathrm{m}^{2}$. The primary-frame beams are placed every 10 stories according to the actual project designs and code requirements for the strengthened story. Regardless of braces buckling under compression, buckling-restrained braces [20] are used in this study. To improve the ability of steel tube to confine concrete, multicell concrete-filled steel tubular mega columns are used as primary columns with reference to the section of mega columns in Guangzhou East Tower [21, 22]. Table 1 summarizes the member sizes and mechanical properties for beams, columns, shear walls, and braces at different stories, and Figure 3 gives the schematic diagram. The mega columns have concrete-filled steel tube (CFT) cross sections that are simulated by fiber model [23], and other members are reinforced concrete sections, including the mega beams [24].

Taking $5 \mathrm{MBC}$ as the main analysis model, another 15 structural models were obtained by adjusting the parameters of the main components (e.g., the thickness of the shear walls, the height of coupling beams, the height of the primary-frame beams, the height of the primary-frame columns, and cross-sectional area of braces). The resulting models are named 5MBC-C\#\#, 5MBC-LL\#\#, 5MBC-ZL\#\#, $5 \mathrm{MBC}-\mathrm{Z} \#$, and 5MBC-B\#\#, respectively, where “\#\#” denotes a number. The letters $\mathrm{C}, \mathrm{LL}, \mathrm{ZL}, \mathrm{Z}$, and $\mathrm{B}$ represent the thickness of the shear walls, the height of the coupling beams, the height of the primary-frame beams, the height of the primary-frame columns, and cross-sectional area of the braces, respectively. The associated numbers (\#\#) indicate the relative dimensions of the parameters. For example, $5 \mathrm{MBC}-\mathrm{Z} 08$ indicates that the height of the primary-frame column section is 0.8 times that of $5 \mathrm{MBC}$, and the remaining parameters are the same.

Considering the second-order effect of gravity, the nonlinear static and dynamic analyses of the model structures were performed using the finite element software Perform-3D. The load distribution based on the first mode was used in nonlinear static pushover analysis. In this model, Q345 steel with the yield stress of $345 \mathrm{MPa}$ was chosen for the tube of the primary columns and the braces, and HRB400 rebar with the yield stress of $400 \mathrm{MPa}$ was used for the concrete members. Concrete types C60 and C40 were chosen for the primary structure (including shear walls) and secondary structure, respectively. The constitutive relation of steel plates and rebars is an ideal bilinear elastic-plastic model without strength degradation. The constitutive relation of steel-tube-confined concrete [25] is the constitutive model of steel-tube-confined concrete with strength degeneration. The concrete constitutive model of reinforced concrete wall members and primary-frame beams is taken into account for Mander concrete [26] with strength degradation. The constitutive curves of all materials are shown in Figure 4. The inelastic fiber elements 


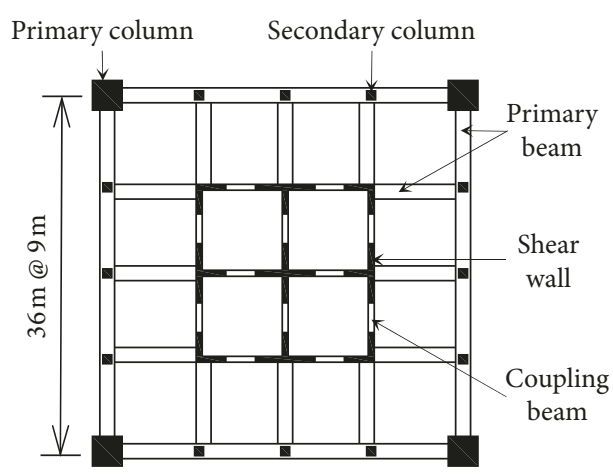

(a)

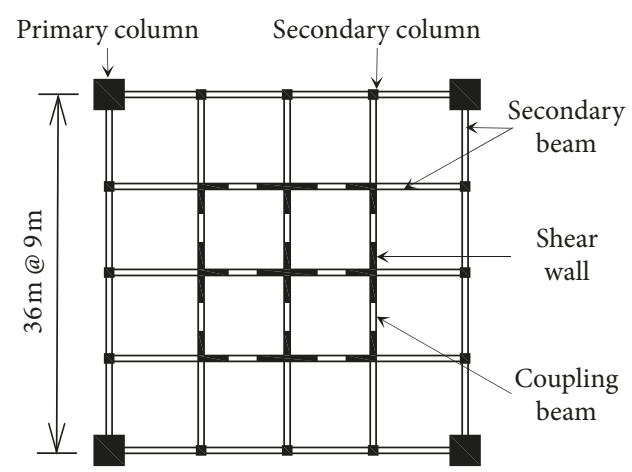

(b)

FIGURE 1: Plan of primary frame- and secondary frame-braced structure analysis models: (a) primary story plan; (b) secondary story plan.

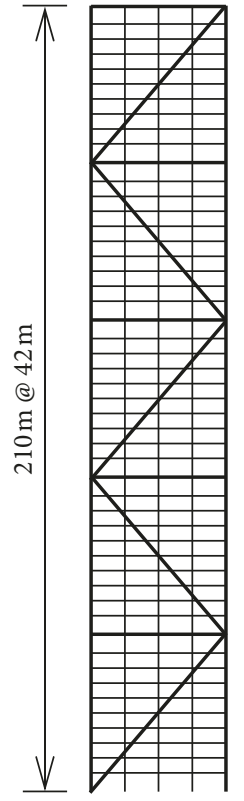

(a)

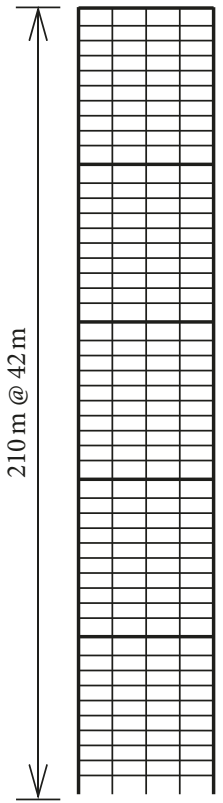

(b)

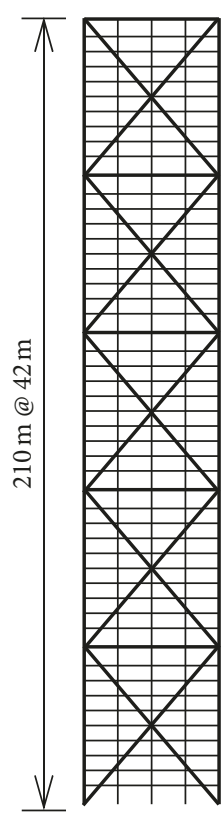

(c)

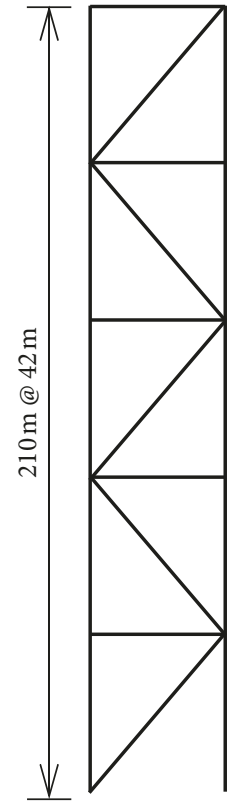

(d)

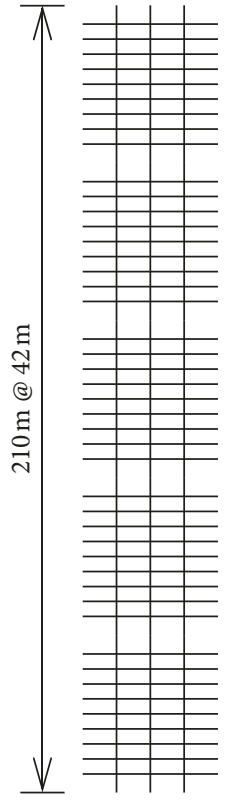

(e)

FIGURE 2: Elevation of 50-story primary frame- and secondary frame-braced structure analysis models: (a) 5MBC; (b) 5MC; (c) 5MXBC; (d) primary frame of $5 \mathrm{MBC}$; (e) secondary frame of $5 \mathrm{MBC}$.

TABLE 1: Selected members for 50-story analysis structures (unit: $\mathrm{mm}$ ).

\begin{tabular}{|c|c|c|c|c|c|}
\hline Members & Stories & Size & Concrete grade & Steel grade & Details \\
\hline Primary columns & $1-50$ & $3000 \times 3000$ & $\mathrm{C} 60$ & Q345 & Q345-t50 \\
\hline Primary beams & $10,20,30,40,50$ & $1500 \times 3000$ & C60 & HRB400 & $33 \Phi 32+33 \Phi 32$ \\
\hline \multirow[t]{2}{*}{ Secondary beams } & $1-50$ & $300 \times 600$ & $\mathrm{C} 40$ & HRB400 & $4 \Phi 25+4 \Phi 25$ \\
\hline & $1-10$ & $900 \times 900$ & & & $24 Ф 36$ \\
\hline \multirow[t]{3}{*}{ Secondary columns } & $11-30$ & $800 \times 800$ & $\mathrm{C} 40$ & HRB400 & $20 \Phi 36$ \\
\hline & $31-50$ & $700 \times 700$ & & & $16 Ф 36$ \\
\hline & $1-10$ & 600 & & & \\
\hline \multirow[t]{3}{*}{ Shear walls } & $11-30$ & 500 & C60 & НPB400 & $\rho s=0.6 \%$ \\
\hline & $31-50$ & 400 & & & \\
\hline & $1-10$ & $600 \times 1200$ & & & $12 \Phi 22$ \\
\hline \multirow[t]{2}{*}{ Coupling beams } & $11-30$ & $500 \times 1200$ & C60 & НРB400 & $10 \Phi 22$ \\
\hline & $31-50$ & $400 \times 1200$ & & & $8 \Phi 22$ \\
\hline Braces & $1-50$ & $600 \times 600 \times 50$ & - & Q345 & - \\
\hline
\end{tabular}




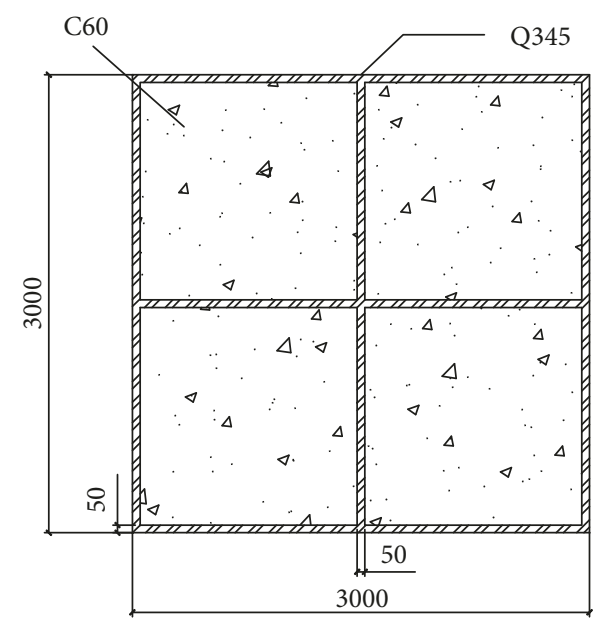

(a)

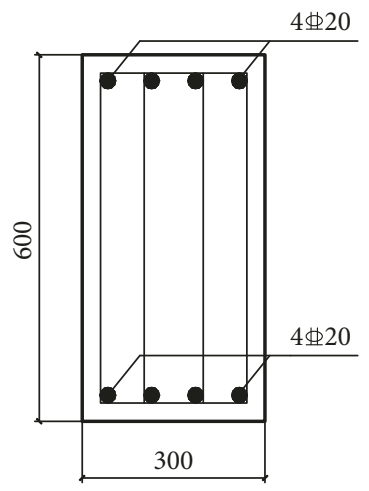

(c)

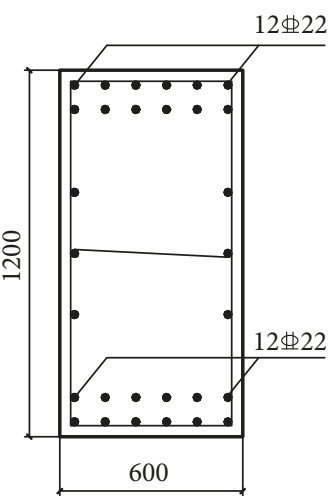

(d)

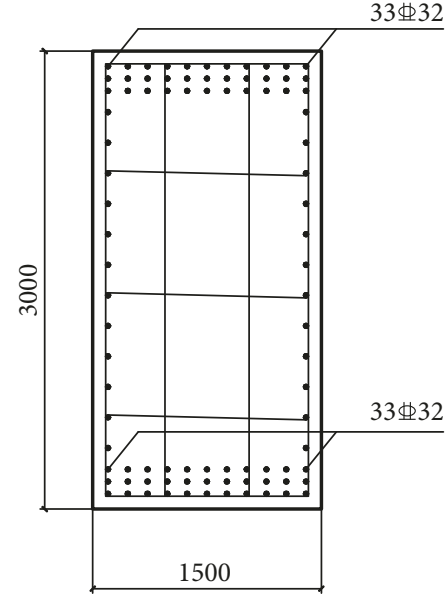

(b)

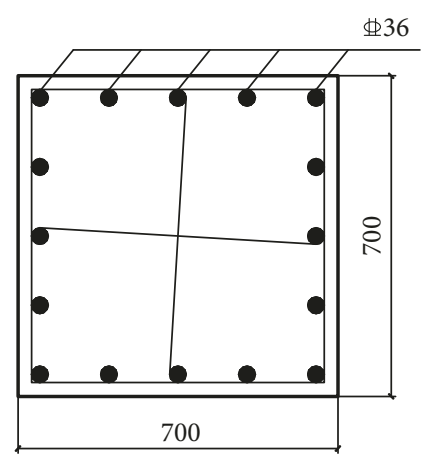

(e)

FiguRE 3: Schematic diagram of representative cross sections: (a) primary column; (b) primary beam; (c) secondary beam; (d) coupling beams with the width $600 \mathrm{~mm}$; (e) secondary column.

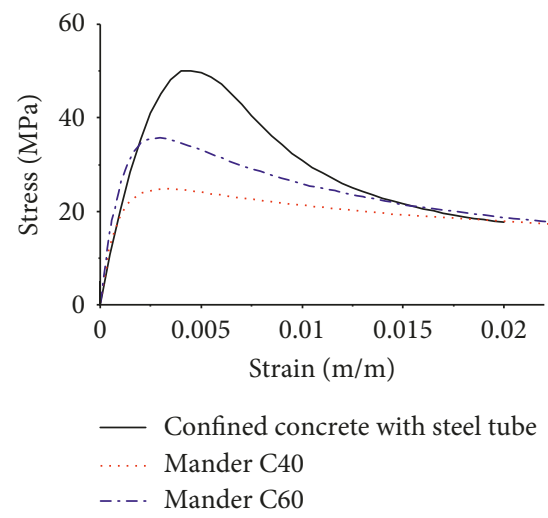

(a)

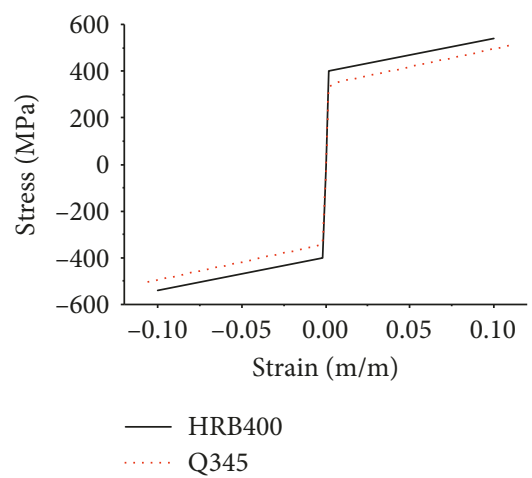

(b)

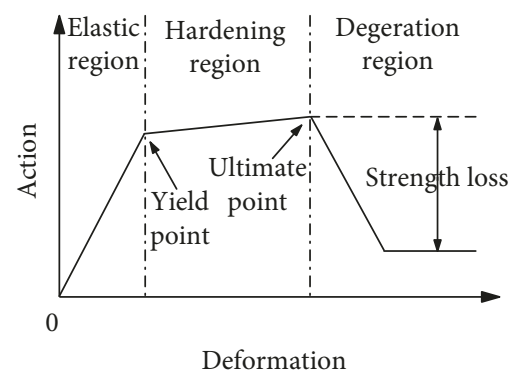

(c)

Figure 4: Constitutive curve for concrete, steel, and plastic hinge model. (a) Concrete. (b) Steel. (c) Plastic hinge model.

were used to model the primary-frame columns, primaryframe beams, secondary-frame columns, and reinforced concrete shear walls. The behavior of all of its fibers with various materials determines the behavior of a fiber cross section. The nonlinear characteristics of the secondaryframe beams and coupling beams were modeled by curvature-type plastic hinges and shear hinges [27] considering the strength loss with large deformation (Figure 4). In this paper, the strength loss of each section can be considered in the nonlinear deformation process by the strength loss of the fiber material and the strength loss of the plastic hinge. 


\section{Nonlinear Static Analysis of Model Structures}

3.1. Yield Order of Components. Figure 5 shows the pushover curves of three model structures and the first yielding points of the main components on the curves. Based on the structure-capacity-spectrum seismic performance evaluation method [28], the performance points of an intensity 7 frequent earthquake and an intensity 7 rare earthquake were obtained by overlapping the structure capacity spectrum and the demand spectrum of the frequent earthquake and rare earthquake. According to the results of the pushover analysis, the stiffness and strength of the 5MXBC are almost two and four times greater than those of $5 \mathrm{MBC}$ and $5 \mathrm{MC}$, respectively. This demonstrates that the megabraced framecore tube structure system has stronger lateral stiffness and bearing capacity than that of the mega-frame-core tube structure system. In primary and secondary structures, the synergistic action of interior and exterior tube greatly improves the redundancy of the structure and enhances the structure's bearing capacity and ductility. When the concrete of primary columns is crushed, the steel tubular primary columns provide sustained bearing capacity, which slows down the reduction of the bearing capacity of CFT columns. Based on the above characteristics, the primary and secondary structures exhibit high ductility and good bearing capacity under earthquake, and the bearing capacity tends to decline slowly under pushover actions. The use of core walls and mega braces increase the redundancy of megabraced frame-core tube structure, which makes the declination of the base shear even slower than that of concrete moment resisting frames [29].

Figure 6 shows the plasticity development process of the megabraced frame-core tube structure system, taking the $5 \mathrm{MBC}$ base shear force-roof displacement of top story curve as an example. For ease of explanation, the elevation parallel to the horizontal load direction is the web elevation, and the elevation perpendicular to the horizontal load direction is the flange elevation. The structural analysis starts from zero displacement. The plastic hinges of the coupling beams appear at displacement A because of the increasing moment at the end of the coupling beams. However, the base shear force still increases due to the high stiffness of the exterior tube. The braces yield at displacement $B$ while the rate of increase in base shear force decreases because of significant degradation in structural stiffness. At displacements of C, D, and $\mathrm{E}$, the plastic hinges appear on the secondary-frame beams and columns. And, plasticity mainly develops in the secondary frame. The concrete at the bottom of the core walls yields at displacement $F$. The end of the primary-frame beams in the web elevation enters the plastic stage at displacement $\mathrm{G}$ because of the growing bending moment. At displacement $\mathrm{H}$, the concrete of the primary columns is constantly under pressure into the plastic stage. That is because the confinement effect of the steel tube [30] ensures that the bearing capacity of concrete in the tube continues to rise due to the effect of steel tubes. Steel yielding of core walls and primary columns occurs at displacements of $\mathrm{J}$ and $\mathrm{K}$, respectively. However, the hoop effect continues to function, and the compressive strength of the confined concrete

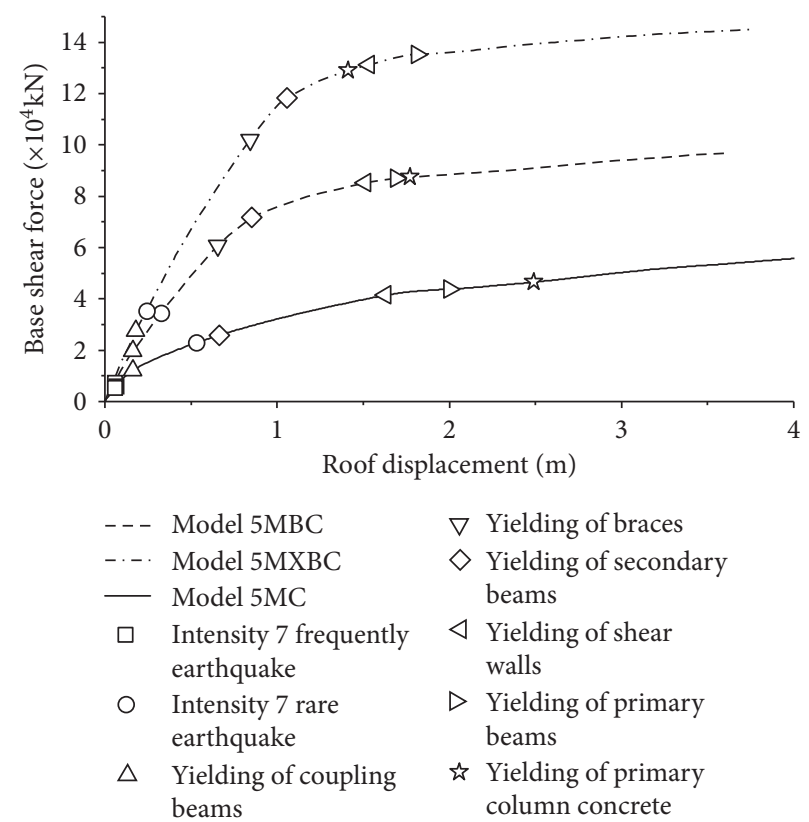

Figure 5: Pushover curves of three model structures: 5MB, 5MBC, and $5 \mathrm{MXBC}$.

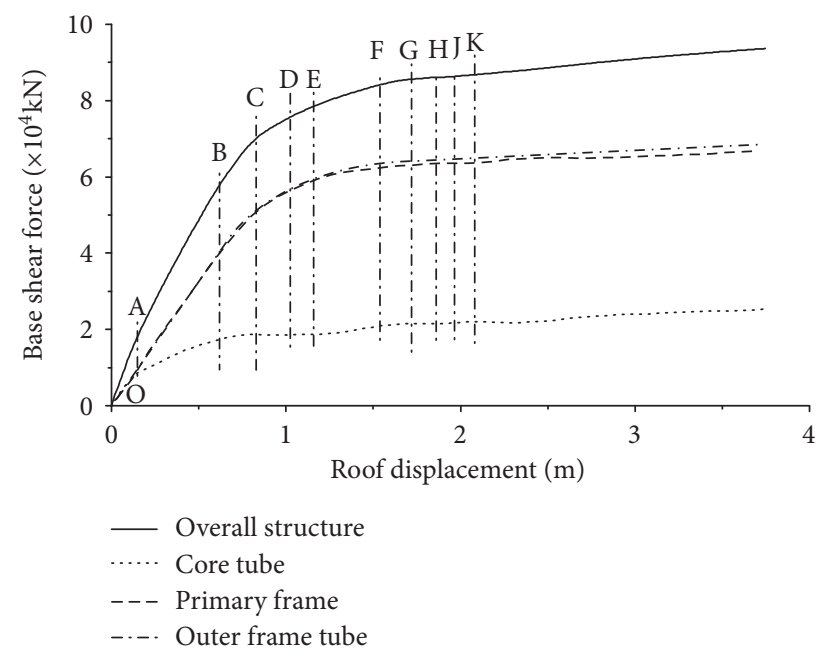

FIGURE 6: Pushover curves of model 5MBC contained the following details: overall structure, core tube, primary frame, and outer frame tube.

increases. Some concrete in the steel tube cells is confined by the steel tubes in the elastic stage, and the primary-frame columns still have strength reserve [31]. In an overview of the whole pushover process, the yield order of the components is coupling beams, braces, secondary frame, core walls, primary beams, and columns. A plastic hinge from the interior tube to the exterior tube stretches from the secondary frame to the primary frame. The variety of yield components and the reasonableness of the yield order indicate that the development process of plasticity is reasonable from the viewpoint of seismicity.

Comparing the impact of different brace patterns, Figure 5 shows that the component yield order of $5 \mathrm{MB}$ 
model is basically the same as that of $5 \mathrm{MBC}$ and $5 \mathrm{MXBC}$ models. In contrast, primary-frame columns yield before core walls and primary beams in model 5MXBC. The $\mathrm{X}$-braces greatly improve the exterior tube stiffness, so that the exterior tube bears more shear force than that in the $5 \mathrm{MC}$ and $5 \mathrm{MBC}$ models. The shear force and bending moment are mainly resisted by the primary columns after the braces yield. And the primary columns can reach the bearing-capacity limit more easily than the core walls and primary beams. This yield order, in which the primary columns yield before the primary beams, rapidly decreases the exterior-tube bearing capacity and even causes the structure to collapse. In the structural design, we should further weaken the primary beams or braces to ensure the yield order in which the primary beams yield before the primary columns.

The influence of these parameters (e.g., the thickness of the shear walls, the height of coupling beams, the height of the primary-frame beams, the height of the primary-frame columns, and the cross-sectional area of braces) on the development process of structure plasticity was analyzed in the 5MBC model. As shown in Figure 7, upon changing the height of the primary beams and the cross-sectional area of the columns, the primary columns may be too weak or the primary beams may be too strong. In this case, the damage to the primary column will develop faster, which causes the primary columns to enter the yield state earlier. The enhancement of braces significantly increases the internal force of the primary columns, which also causes the primary columns to enter the yield state earlier. Changing the core walls and coupling beams has little effect on the yield order. In terms of bearing capacity, changes to the primary beams, primary columns, and mega braces strongly influence the bearing capacity, indicating that the stiffness and strength of the exterior tube significantly affect the overall structural bearing capacity.

\subsection{Plastic Distribution Characteristics of the Exterior Tube.} In the megabraced frame-core tube structure system, the exterior tube is an important part of the structural lateral resistance system. The plastic distribution characteristics of the exterior tube are particularly important for the overall seismic performance when the structure enters the plastic stage. Figure 8 depicts the plastic hinge formation in the web-side frame (parallel to the direction of lateral load) of the 50-story mega-diagonal-braced frame-core tube structure (5MBC). The empty and solid circles show that the members yield by compression plus flexure $\left(\Delta_{\mathrm{cy}}\right.$ in Figure 8$)$ and those by tension plus flexure $\left(\Delta_{\mathrm{y}}\right.$ in Figure 8$)$, respectively. The empty and solid squares show that the members reach the limit state of life safety by compression plus flexure and by tension plus flexure. And the $\delta$ in Figure 8 represents the maximum interstory drift in all stories. Note that the first yielding occurs in the braces at the lower-middle story of the web-side frame and evolves toward the upper and lower stories.

Next, the secondary-frame beams of the braced yielding story yield and the yielding region expands with the evolution of brace yielding, as shown in Figure 8(a). When the speed of the plastic evolution of the braces decreases (Figure 8(b)), the plastic hinges also occur on the secondary columns connected to the primary frame beams. This is caused by the combined load of axial compression and the bending moment. When the plastic hinges are almost fully developed in the secondary beams of the brace-yielding story, the primary-frame beams enter the plastic stage (Figure $8(\mathrm{c})$ ). At the maximum interstory drift of $2 \%$, the primary column at the bottom of the compression side reaches its limit and enters the plastic stage. By checking the internal force of the yielded primary column, we find that the contribution of axial force to the primary-column failure basically equals the bending moment. We can consider it as the critical-failure mode of the small and large eccentricity failure modes. Note that the yielding of the secondary-frame beams evolves with the plastic development of the braces during the development of structural plasticity. The plastic region of the secondary beams and braces concentrates on the middle and lower stories of the mega-diagonal-braced frame structure system. The reason is that the yield of the braces increases the shear-deformation ratio of adjacent primary columns and decreases the axial-deformation ratio. And this increases the deformation of adjacent secondary beams, which yield fully.

Figure 9 plots the distribution of plastic hinges of members in the web-side frame of a 50-story mega-X-braced frame structure $(5 \mathrm{MXBC})$. More braces enter the yielding state before the secondary beams yield as shown in Figure 9(a). Because of the effect of X-braces, the primary columns yield before the secondary columns, as shown in Figure 9(b), and the contribution of axial force to primary-column failure is significantly greater than that of $5 \mathrm{MBC}$ (shown in Figure 8). The failure of the primarystructure columns clearly shows the characteristics of a small-eccentricity failure mode, indicating worse ductility. When the maximum interstory drift reaches 0.02 , the structural plastic region is mainly concentrated below the middle story, and the plastic distribution region is smaller than that of 5MBC. Considering the failure mode of the component and the area of plastic distribution, the structural ductility of $5 \mathrm{MXBC}$ is worse than that of $5 \mathrm{MBC}$.

In contrast, the failure of the primary columns in $5 \mathrm{MC}$ is a bending failure mode (large eccentricity failure mode), which can improve the lateral stiffness and ductility. The primary beam connecting the interior tube and the exterior tube can be regarded as a sort of outrigger beam. Without the action of mega braces, the effect of the outrigger beam is significant. The primary beam will enhance the overall sheartype response characteristics [32], and the deformation of primary column deformation will be dominated by bending and shearing rather than tensile deformation. And the ductility of components is the best among the three models, as shown in Figure 10. The region of the plastic component extends over almost the entire web-side frame, resulting in a significant increase in overall ductility, as shown in Figure 11. Note that the full plasticity development of the secondary frame is based on the precondition of the brace yielding, taking $5 \mathrm{MBC}$ and $5 \mathrm{MXBC}$ as references. 


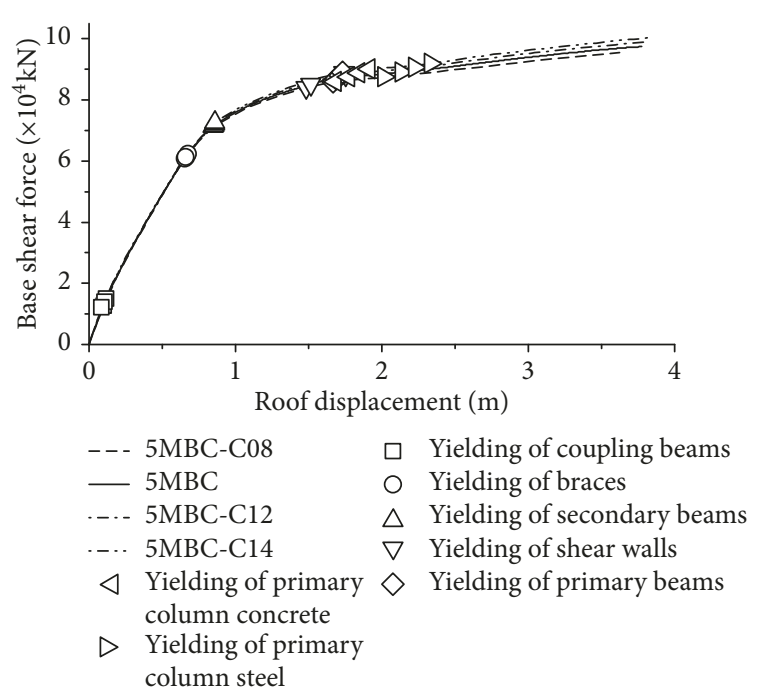

(a)

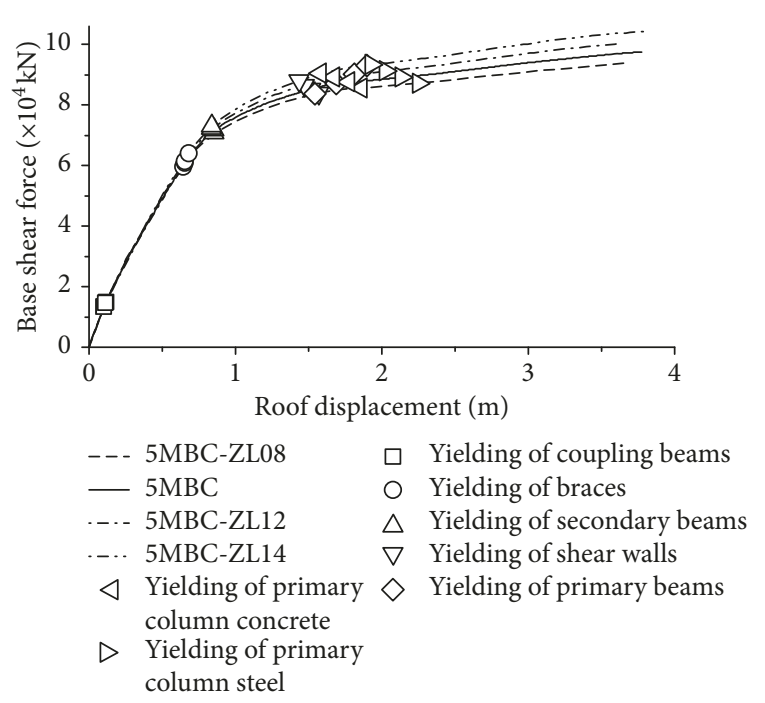

(c)

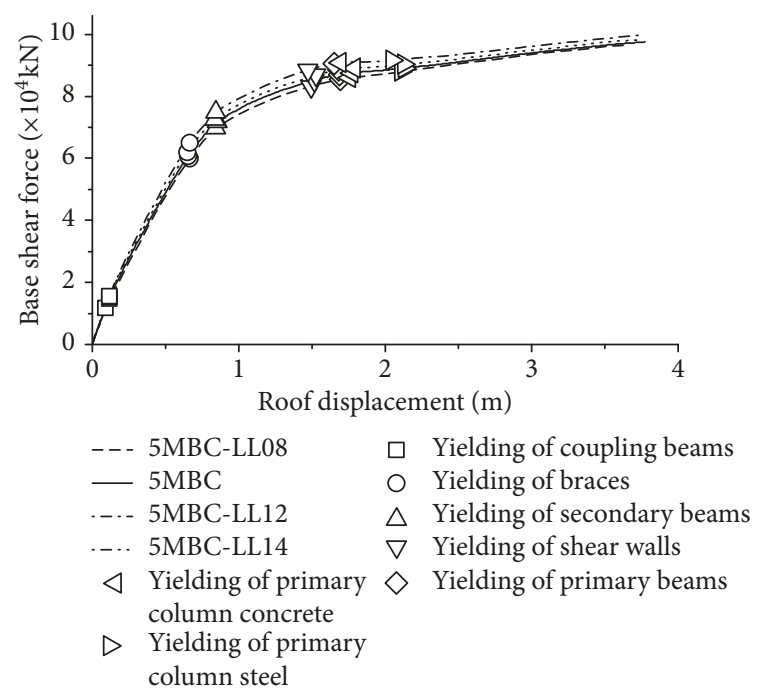

(b)

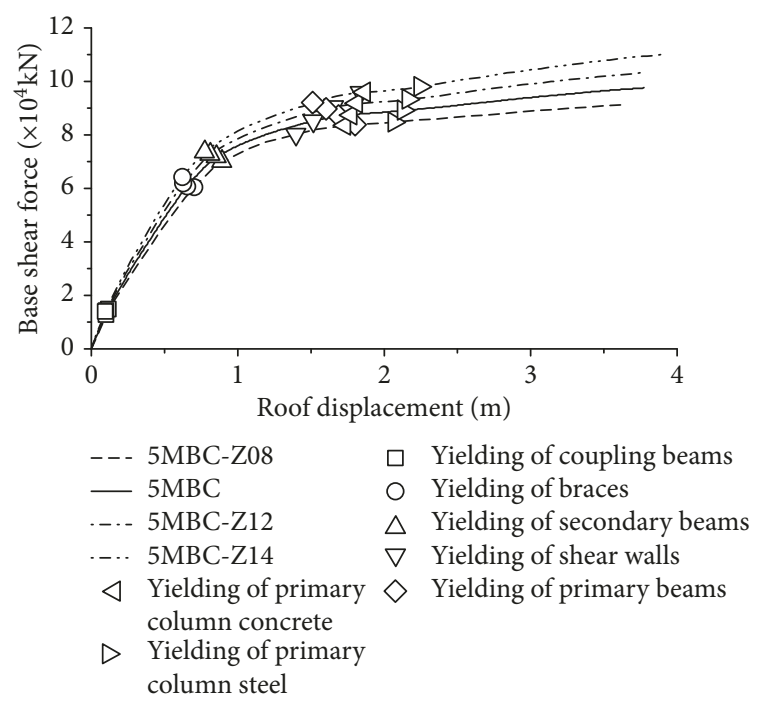

(d)

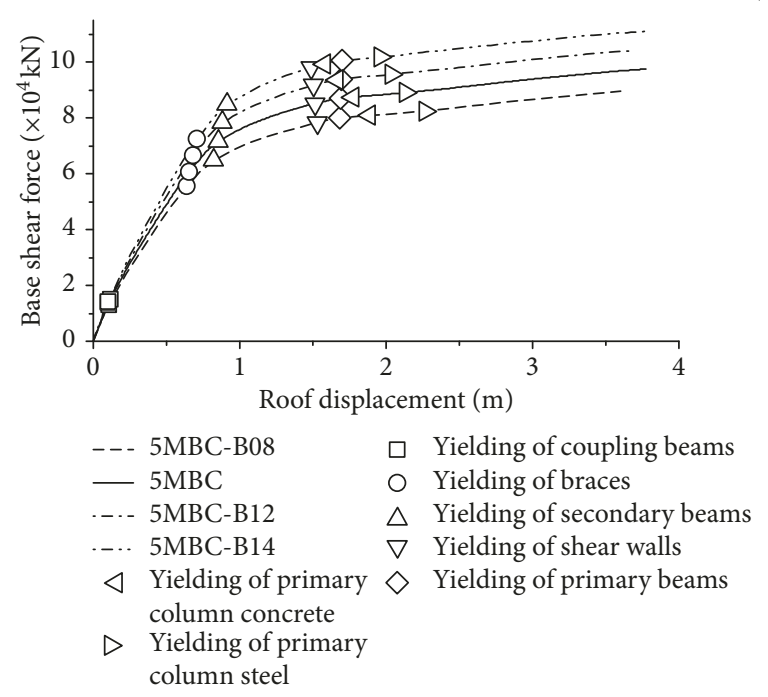

(e)

FigURE 7: Influence of key parameters on structural plasticity development process in model 5MBC: (a) thickness of shear walls, (b) height of coupling beams, (c) height of primary beams, (d) sectional area of primary columns, (e) sectional area of braces. 


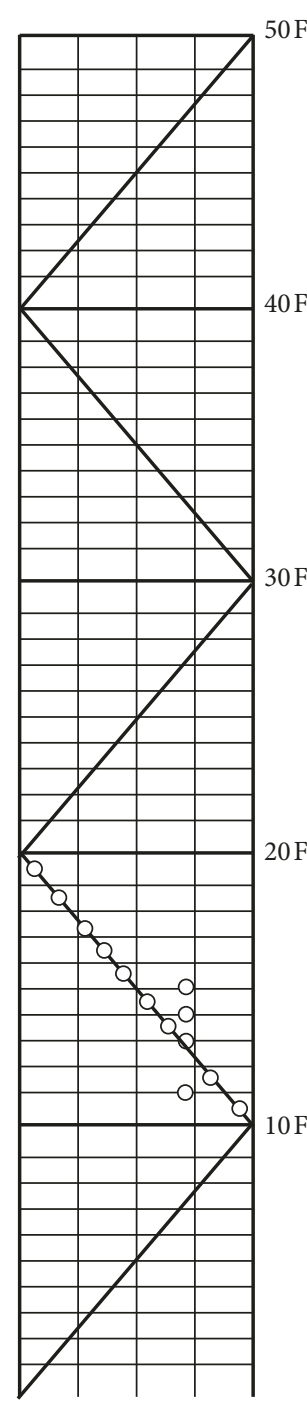

- $\Delta_{\mathrm{y}}$

$\Delta_{\mathrm{cy}}$

$\square$ LS

$20 \mathrm{~F}$
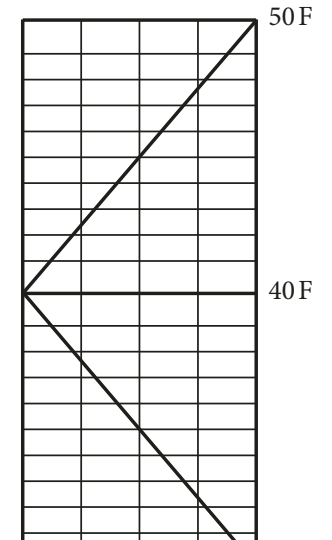

$\mathrm{F}$

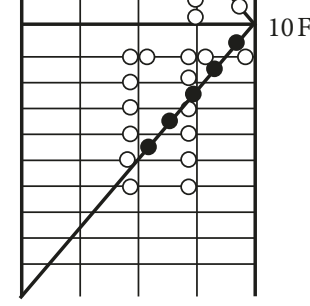

- $\Delta_{\mathrm{y}}$

$\bigcirc \Delta_{c y}$

$\square$ LS

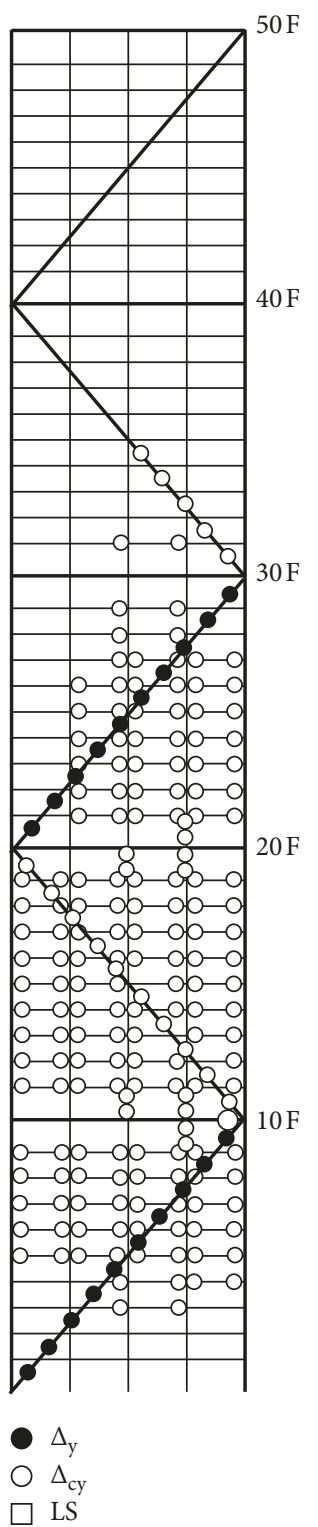

(c)

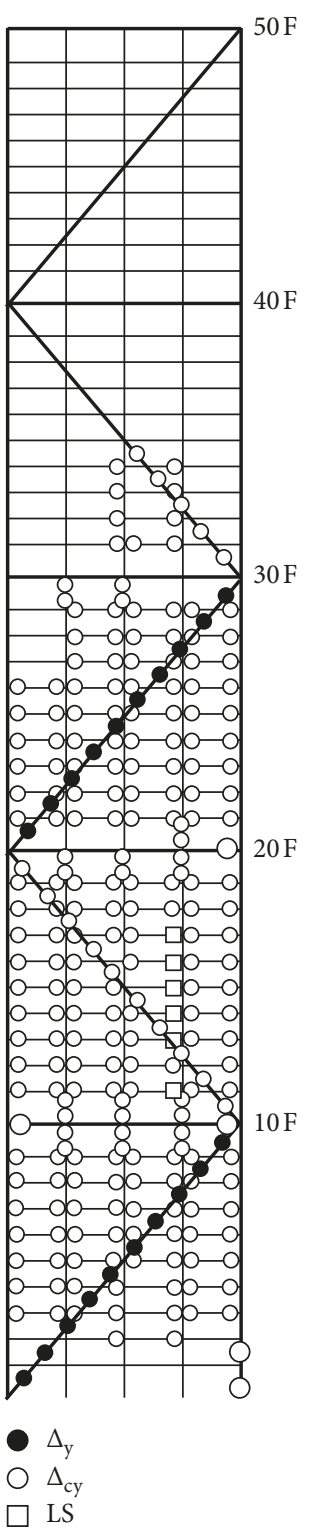

(d)

FiguRE 8: Plastic hinge formation in the web-side frame of model 5MBC: (a) first yield ( $\delta=0.62 \%)$; (b) secondary column yield $(\delta=1.03 \%)$; (c) primary beam yield ( $\delta=1.5 \%)$; (d) at $\delta=2 \%$.

Figure 12 presents the components with plastic deformation in the flange-side (leeward) frame of the three 50story model structures. In all model structures, the columns at the lower stories yield under compression. The secondary columns in the flange-side frame yield because of an increase in axial force and the yielding region of the secondary columns in the flange-side frame expands with the increasing number of braces. The increasing number of braces exacerbates the damage to the primary column detrimental to the ductility of the primary columns and of the entire structure.

Figures 8-12 show that the yielding of the secondaryframe columns only appears at the junction with the primary-frame beams and ground. The plasticity does not extend to other regions. Therefore, in practice, secondary columns should be strengthened, such as increasing section or reinforcement. This can reduce the damage of the secondary column and maintain the carrying capacity of the upper structure.

3.3. Characteristics of Distribution of Internal Force. This section discusses the characteristics of the distribution of internal force by shear force ratio and bending moment ratio at different displacement. The shear force ratio and bending moment ratio represent the ratio of the shear force or bending moment in part of the structure to that in the whole structure [33]. Taking $5 \mathrm{MBC}$ as an example, Figure 13 shows the development process of the internal force ratio regarding the megabraced frame-core tube 


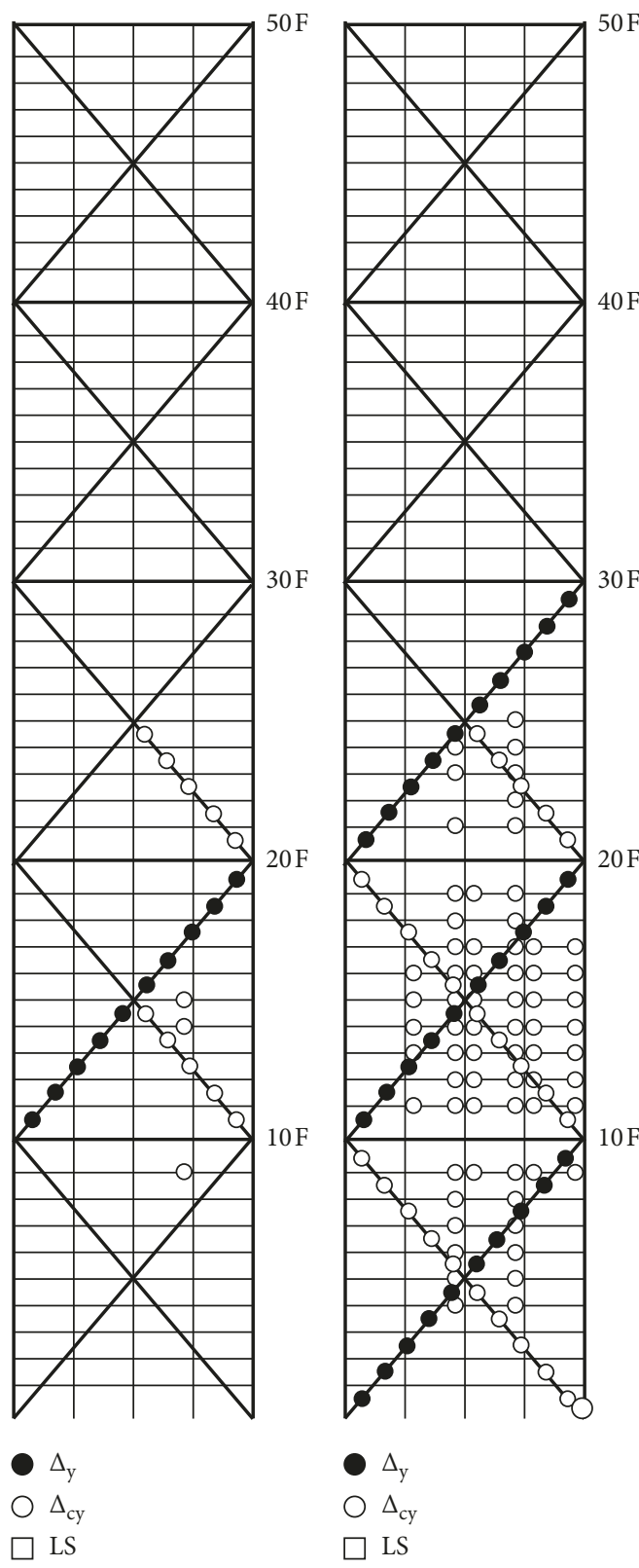

(a) (b)

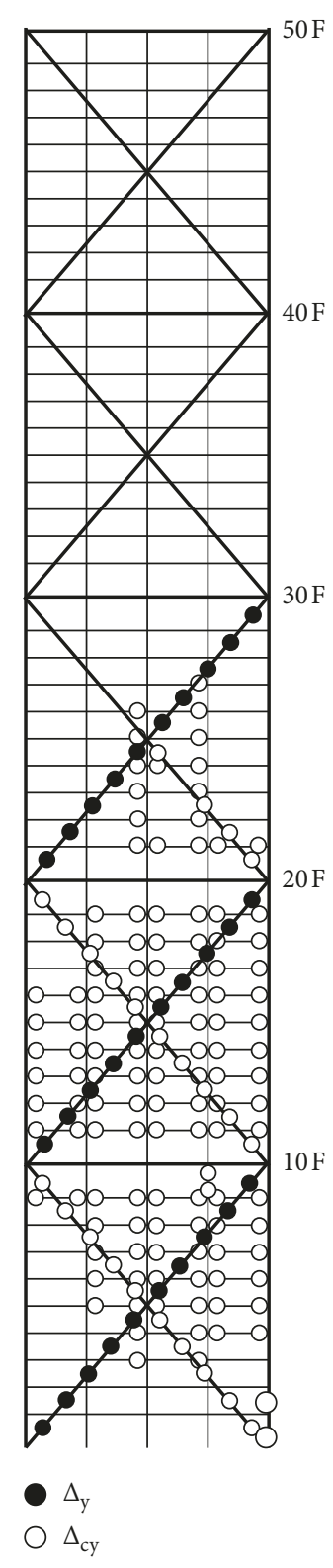

$\square$ LS

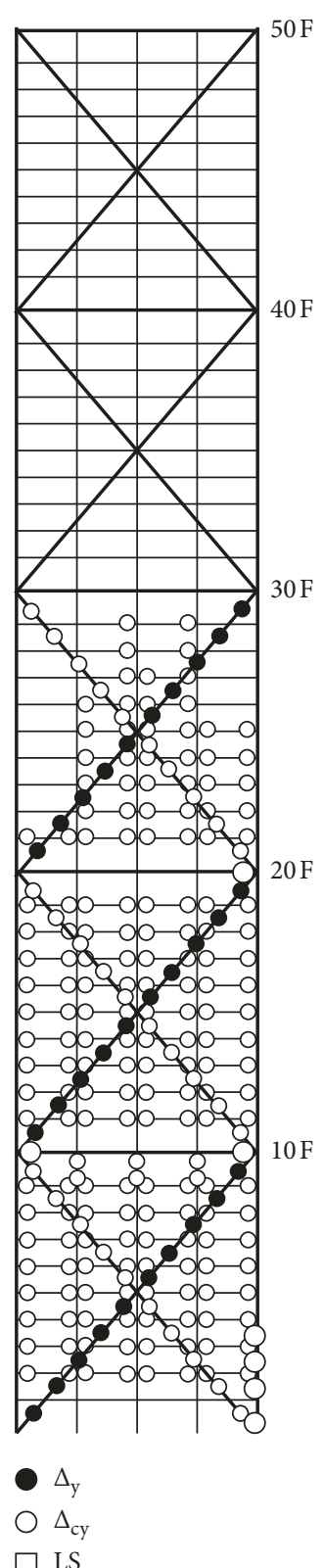

(d)

FIGURE 9: Plastic hinge formation in the web-side frame of model 5MXBC: (a) first yield ( $\delta=0.67 \%)$; (b) primary column yield $(\delta=1.08 \%$ ); (c) secondary column yield $(\delta=1.33 \%)$; (d) at $\delta=2 \%$.

structure. Figure 6 shows that the shear force evolution of the exterior tube is basically the same as that of the primary frame. This indicates that the primary frame contributes most of the exterior tube stiffness.

We divide the internal force distribution process into four stages according to the change of the structural shear force ratio. Before the yielding of coupling beams, the base shear force and bending moments of the primary structure are almost invariable, reaching $47 \%$ and $64.6 \%$. The second stage starts with the coupling beams yielding and ends with the concrete yielding in the secondary columns. The yield of the coupling beams weakens the lateral performance of the core wall, and the shear force ratio and bending moment ratio of the exterior tube increase rapidly. And, it indicates that the shear force substantially transfers from the interior tube to the exterior tube. After the braces and secondary columns enter the plastic stage, the base shear force and bending moment exerted on the primary frame reach about $75 \%$ and $83 \%$. And the shear force ratio of the exterior tube reaches its maximum value. As the roof displacement continues to increase, the shear force ratio of the exterior tube basically remains constant, and the internal force distribution of the interior and exterior tube tends to be gentle. The yielding of the steel in the primary frame columns marks the fourth stage of the internal 


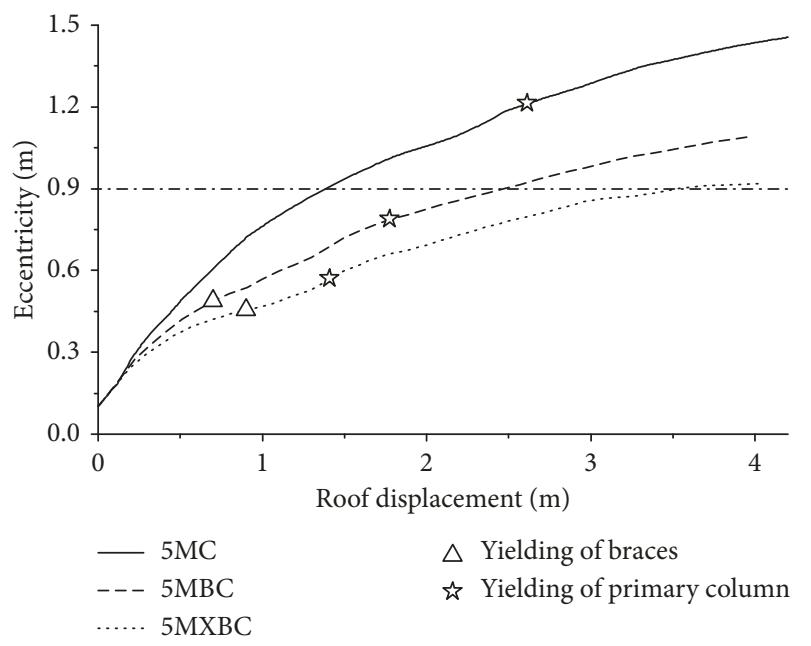

FIGURE 10: The eccentricity curves of primary column in three model structure: 5MB, 5MBC, and 5MXBC (the eccentricity represents the ratio of bending moment to axial force).

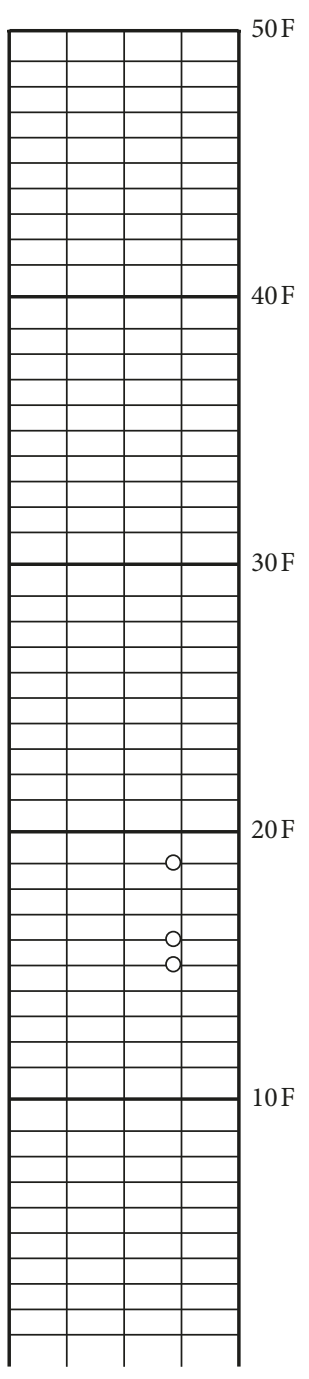

$\bigcirc \Delta_{\text {cy }}$

$\square$ LS

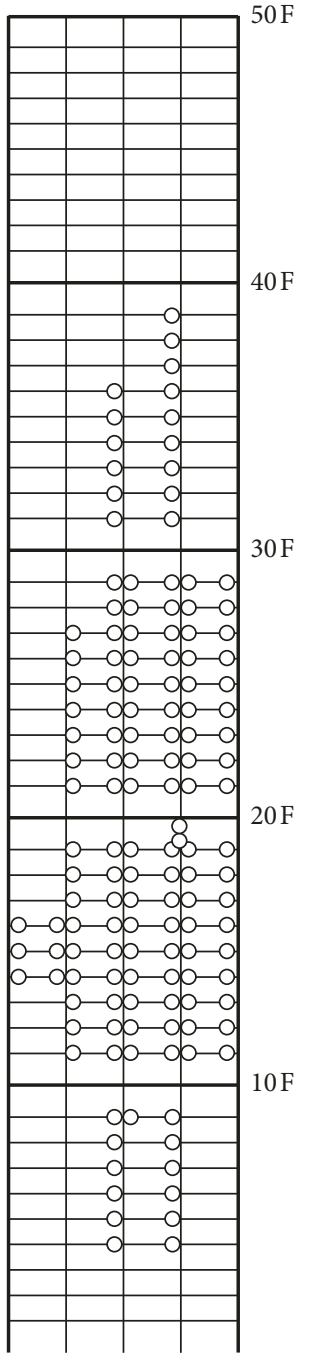

$\Delta_{\mathrm{cy}}$

$\square$ LS

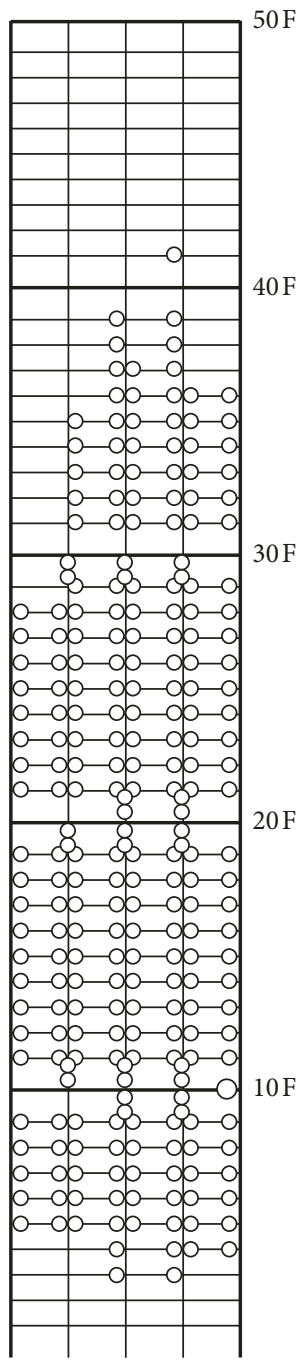

$\bigcirc \Delta_{\text {cy }}$

$\square$ LS

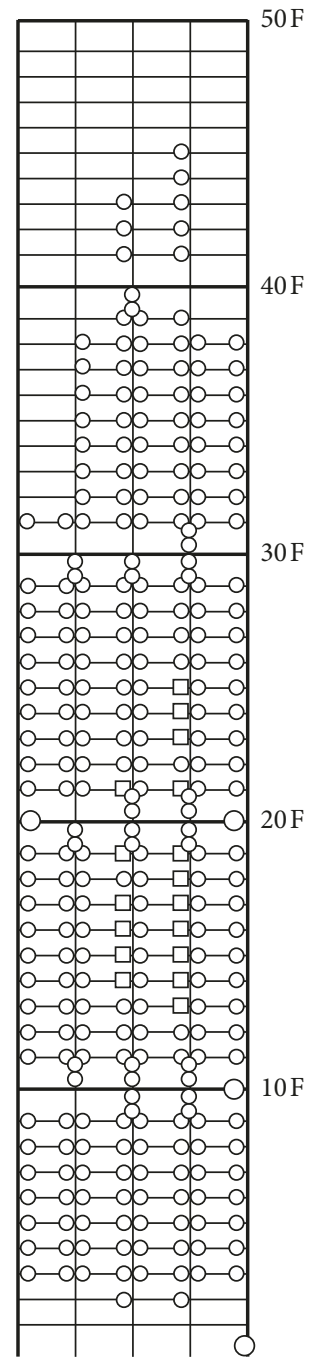

$\bigcirc \Delta_{\text {cy }}$

$\square$ LS

(a)

(b)

(c)

(d)

FIGURE 11: Plastic hinge formation in the web-side frame of model 5MC: (a) first yield $(\delta=0.52 \%)$; (b) secondary column yield $(\delta=1.08 \%)$; (c) primary beam yield $(\delta=1.55 \%)$; (d) at $\delta=2 \%$. 


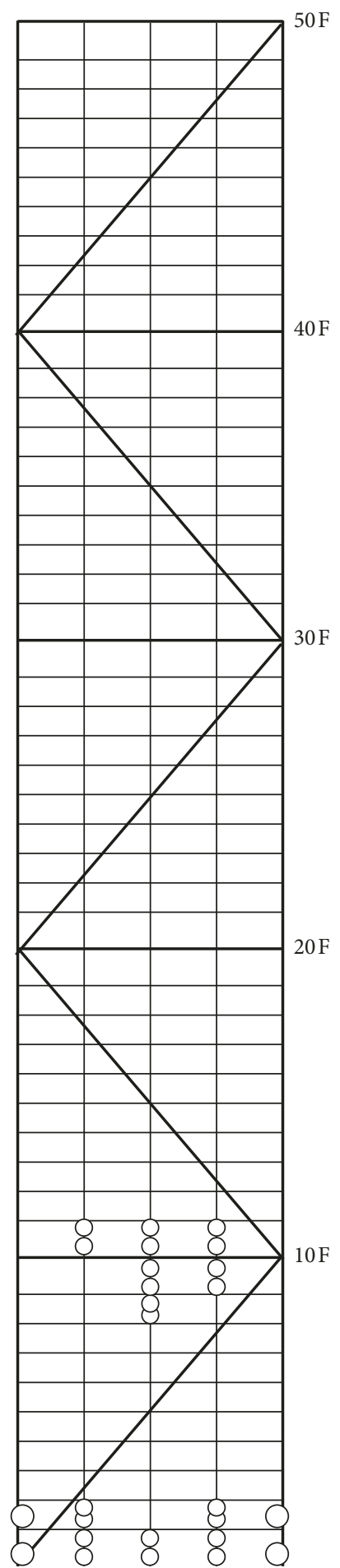
$\Delta_{\text {cy }}$

$\square$ LS

$\mathrm{F}$

$20 \mathrm{~F}$

$10 \mathrm{~F}$
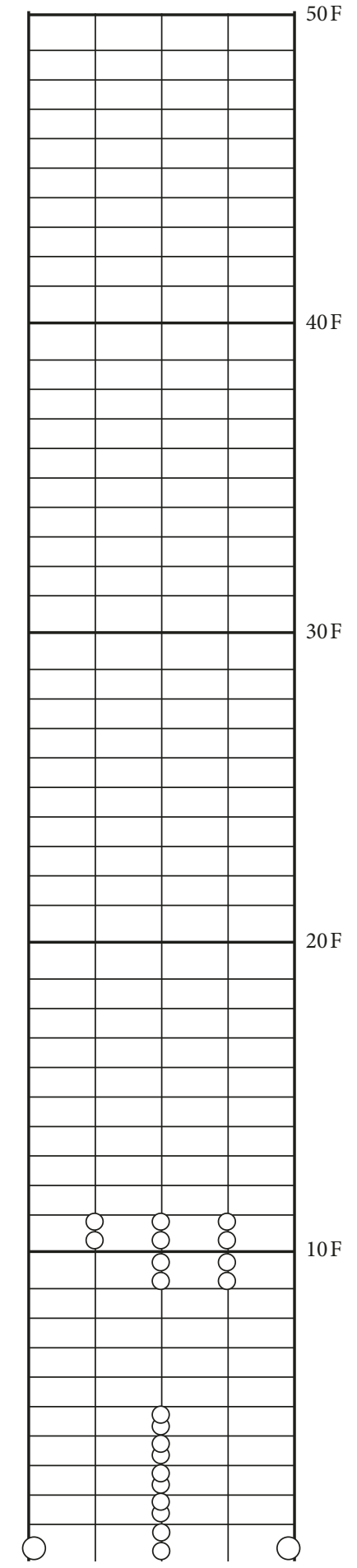

$\Delta_{\mathrm{cy}}$

$\square$ LS

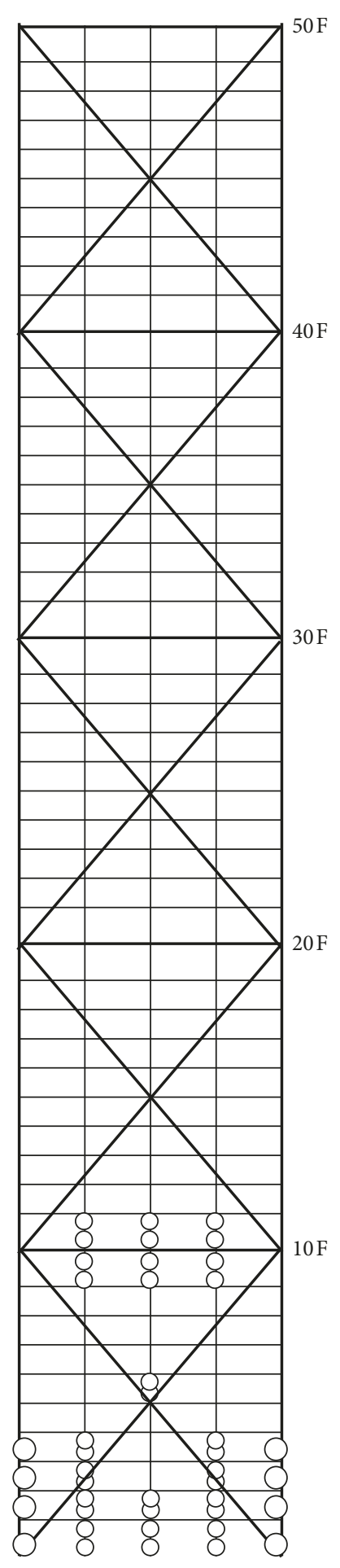

$\Delta_{\text {cy }}$

$\square$ LS

(a)

(b)

(c)

FIGURE 12: Plastic hinge formation in the flange-side frame of three models at $\delta=2 \%$ : (a) $5 \mathrm{MBC}$ model; (b) $5 \mathrm{MC}$ model; (c) $5 \mathrm{MXBC}$ model.

force distribution. The bearing capacity of the primary frame begins to decline and the shear force ratio starts to decrease drastically until the end of the analysis. Throughout this process, the exterior tube takes up most of the bending moment and gradually increases with the degradation of the interior tube coupling beams.

Based on the variation of the shear force ratio (Figure 14), the shear-force distribution stages and stage symbol of model 


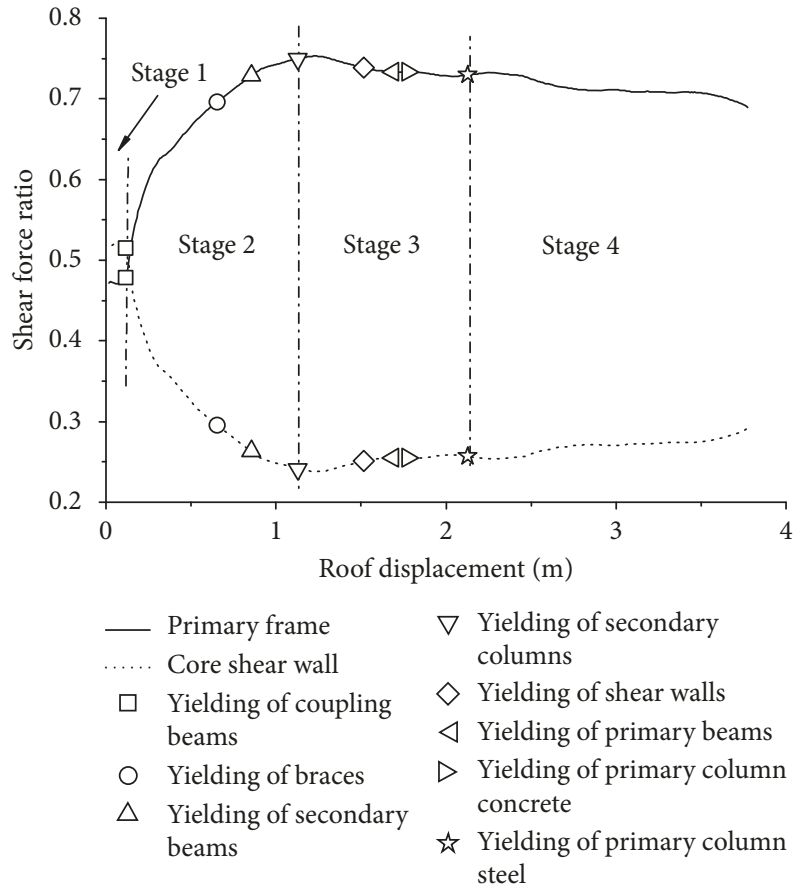

(a)

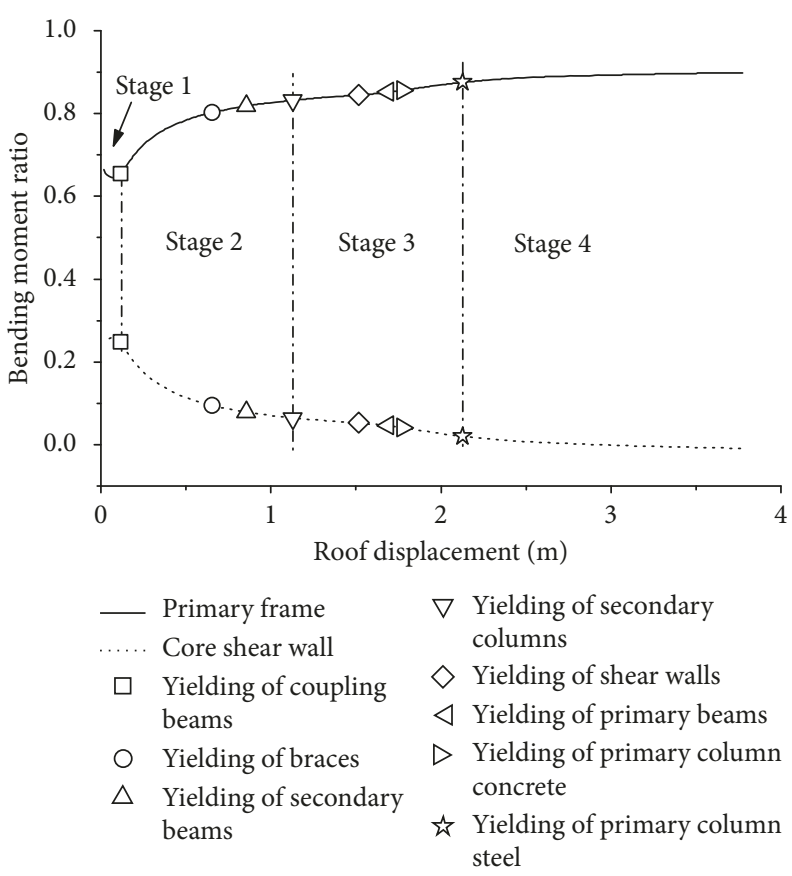

(b)

FIGURE 13: Internal force coefficient of model 5MBC: (a) shear force ratio; (b) bending moment ratio.
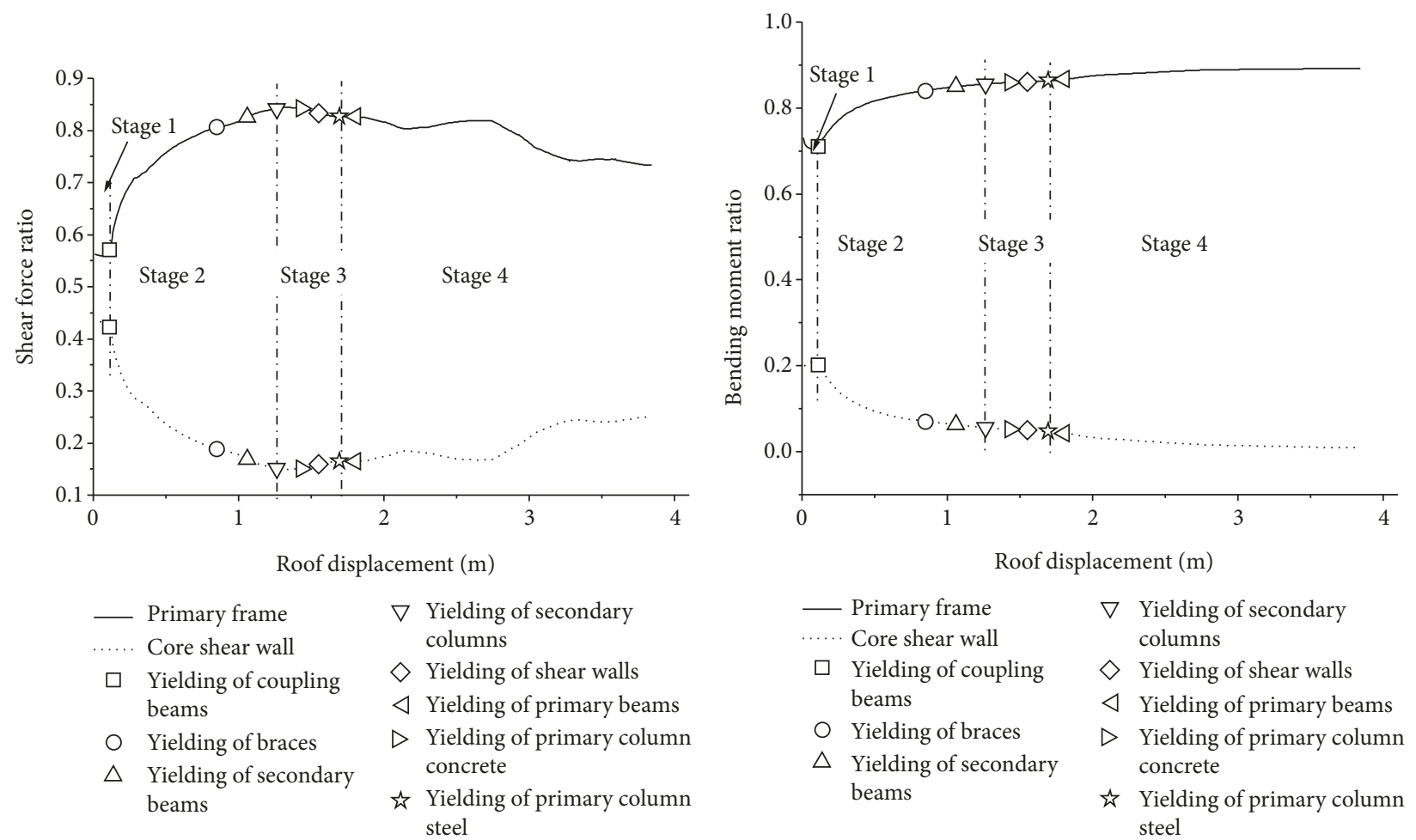

(a)

(b)

FIGURE 14: Internal force coefficient of model 5MXBC: (a) shear force ratio; (b) bending moment ratio. 


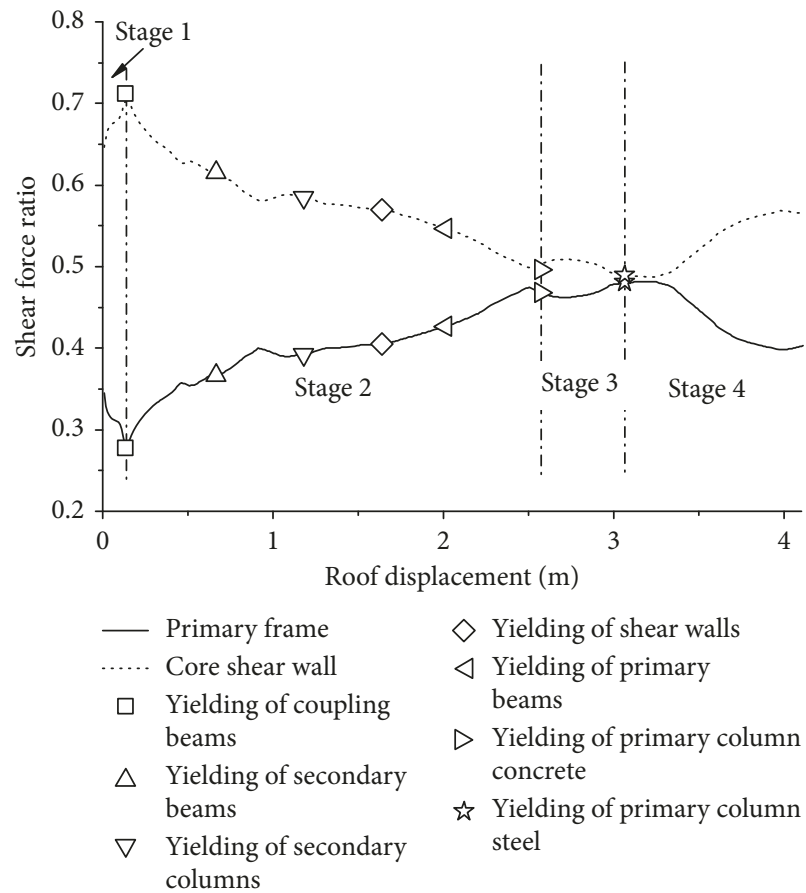

(a)

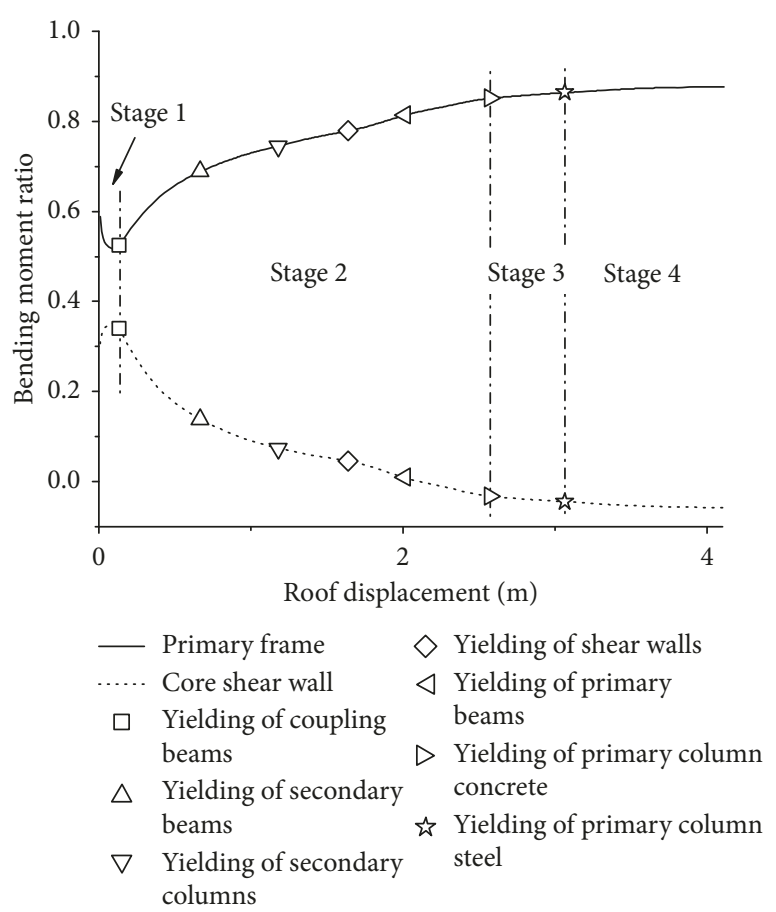

(b)

FIGURE 15: Internal force coefficient of model 5MC: (a) shear force ratio; (b) bending moment ratio.

$5 \mathrm{MXBC}$ are basically the same as those of model $5 \mathrm{MBC}$. Because the braces are strengthened, the exterior tube stiffness for model $5 \mathrm{MXBC}$ exceeds that of $5 \mathrm{MBC}$, which affects the absolute values of the shear force ratio.

On the other hand, the lack of braces in the exterior tube significantly reduces the stiffness of the mega frame, resulting in the different stage divisions of the internal force distribution. As shown in Figure 15, according to the evolution of the shear force ratio, the evolution of the internal force distribution for model 5MC can be divided into three stages. The first and third stages of 5MC are similar to the first and fourth stages of $5 \mathrm{MBC}$, respectively. Unlike the second and third stages of $5 \mathrm{MBC}$, the second stage of 5MC begins with the coupling beams yielding and ends when the steel tubes in the primary columns yield. Without setting braces, the stiffness of the interior tube in model 5MC is much greater than that of the exterior tube. The interior tube bears a greater load, resulting in a faster evolution of damage and a faster degeneration of stiffness. The yield of the secondary columns cannot significantly reduce the stiffness of the external tube. And, the shear force ratio of the external tube continues to increase until reaching a maximum at the end of the stage. Because of the damage to the primary columns, the abrupt decrease of exterior-tube bearing capacity causes the exterior-tube shear force ratio to decrease. That is similar to the fourth-stage process of model $5 \mathrm{MBC}$. The lack of braces reduces the exterior tube stiffness, which causes the internal force to transfer slowly from the interior tube to the exterior tube. When the primary columns yield, the shear force of the interior tube is greater than that of the exterior tube. This shows that the mega braces improve the ability of the exterior tube to serve as a second line of seismic defence. The bending moment ratio of the exterior tube in model 5MC gradually increases and bears most of the bending moment after the coupling beams yield. That is similar to 5MBC and 5MXBC models.

Taking $5 \mathrm{MBC}$ as an example, the different parameters that influence the shear force ratio of the primary frame were analyzed (Figure 16). Adjustments to the different parameters (e.g., wall thickness, coupling-beam height, primary-frame beam height, primary-column height, and cross-sectional area of the braces) do not change the characteristics of the four stages about internal force redistribution. Indeed, the shear force ratio of the primary frame decreases with increasing shear-wall thickness and coupling-beam height and increases with increasing crosssectional area of the primary-frame columns and braces. The impact on the shear force ratio of the primary frame produced by changing the height of the primary beams can be divided into two stages. The effect is insignificant before the secondary columns yield. And increasing the height of the primary beams reduces the shear force ratio of the primary frame after the secondary columns yield. That is because the strengthening of the primary beam accelerates the damage to the primary columns, in turn leading to an accelerated degradation of the lateral stiffness of the primary frame.

3.4. Degradation of Stiffness. This section discusses characteristics of degradation of stiffness by shear secant stiffness and moment secant stiffness [33]. The shear secant stiffness and moment secant stiffness are shown in Figure 17. The 

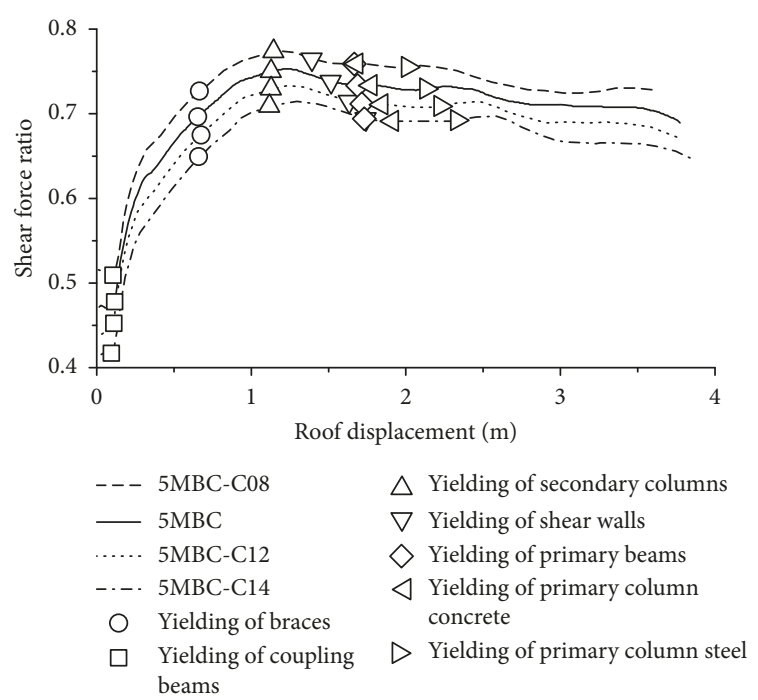

(a)

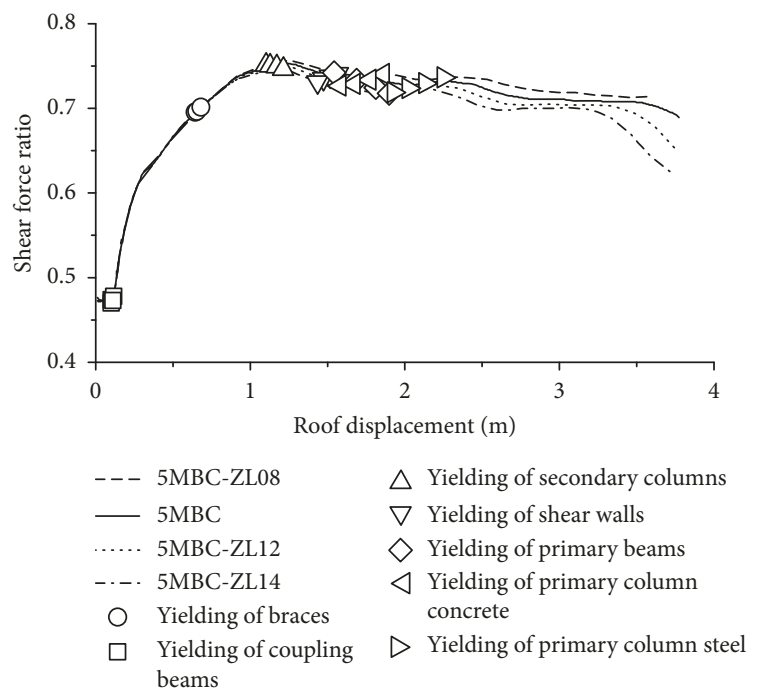

(c)

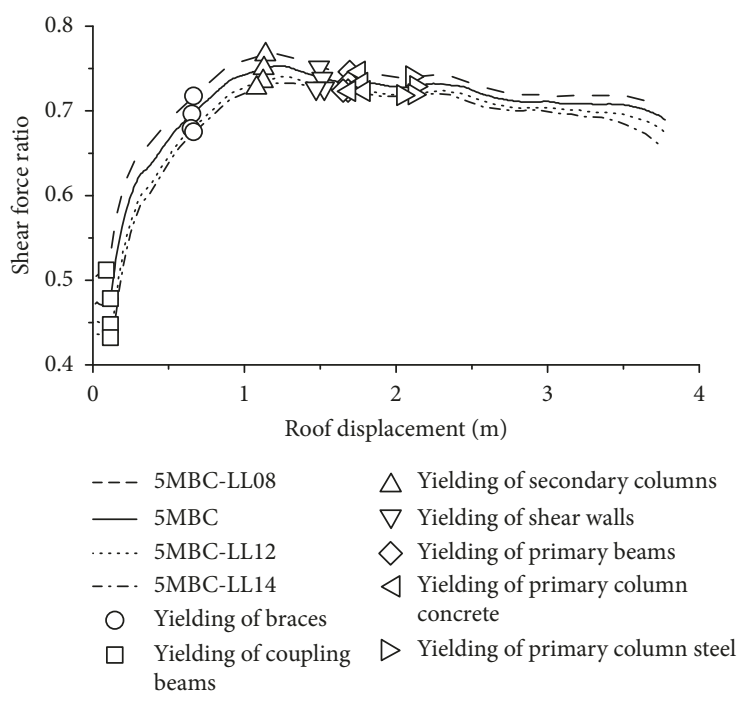

(b)

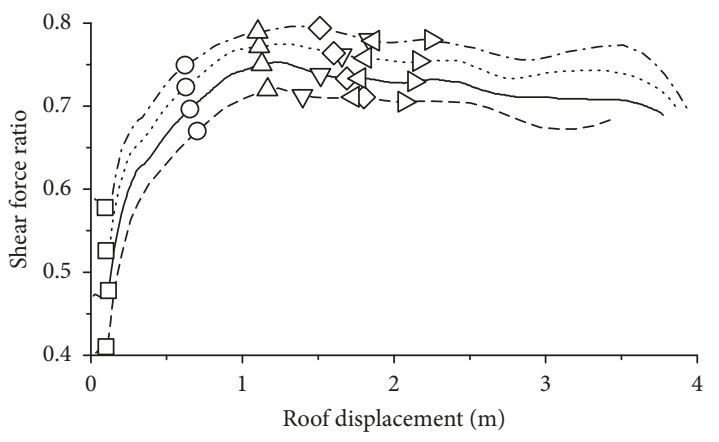

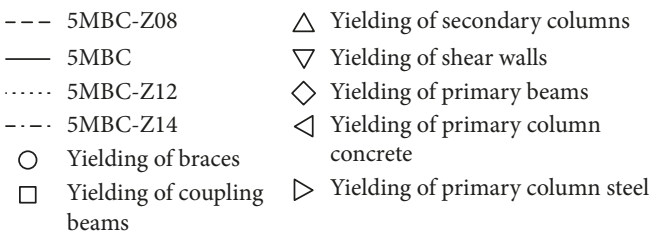

(d)

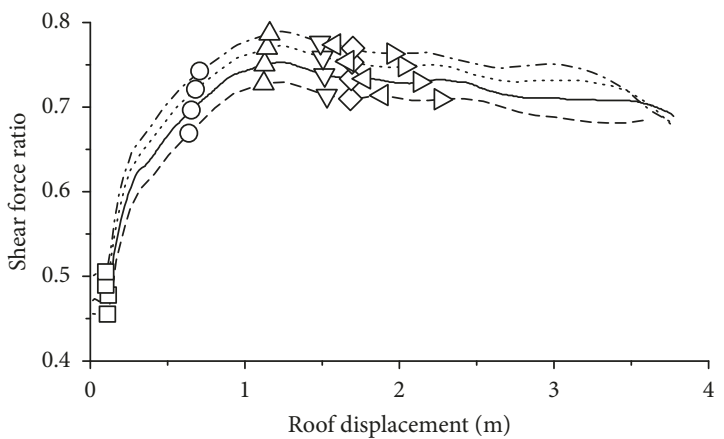

\begin{tabular}{|c|c|}
\hline$-5 \mathrm{MBC}-\mathrm{B} 08$ & $\triangle$ Yielding of secondary columns \\
\hline $5 \mathrm{MBC}$ & $\nabla$ Yielding of shear walls \\
\hline 5MBC-B12 & $\diamond$ Yielding of primary beams \\
\hline 5MBC-B14 & $\triangleleft$ Yielding of primary column \\
\hline Yielding of braces & concrete \\
\hline $\begin{array}{l}\text { Yielding of coupling } \\
\text { beams }\end{array}$ & $\triangleright$ Yielding of primary column steel \\
\hline
\end{tabular}

(e)

FIGURE 16: Influence of key parameters on shear force ratio of primary frame in model 5MBC: (a) thickness of shear walls, (b) height of coupling beams, (c) height of primary beams, (d) sectional area of primary columns, (e) sectional area of braces. 


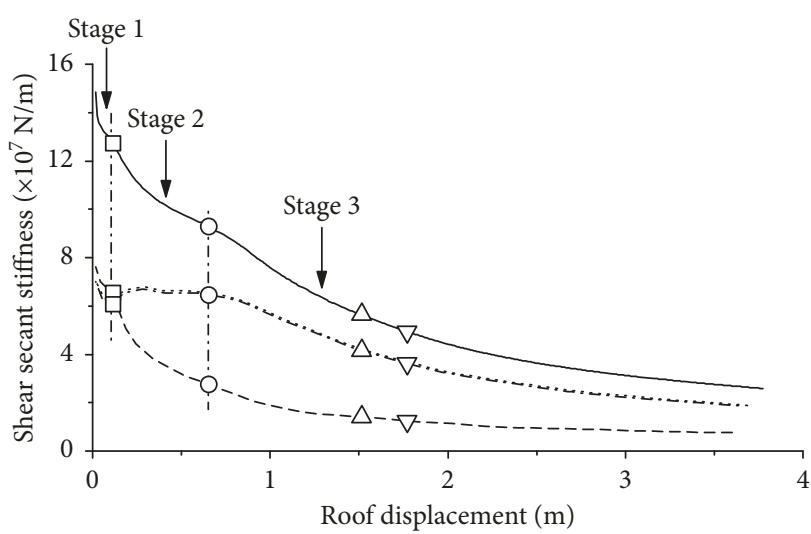

$$
\begin{aligned}
& \text { _ Overall structure } \\
& \text { - - } \text { Core shear wall } \\
& \text {-.- Primary frame } \\
& \text {..... Outer tube }
\end{aligned}
$$

$$
\begin{aligned}
& \square \text { Yielding of coupling beams } \\
& \bigcirc \text { Yielding of braces } \\
& \triangle \text { Yielding of shear walls } \\
& \nabla \text { Yielding of primary column } \\
& \text { concrete }
\end{aligned}
$$

(a)

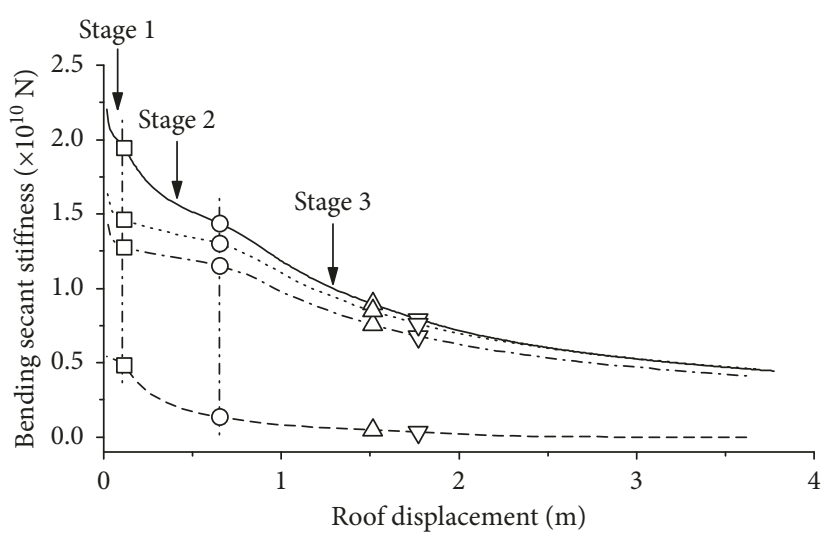

$$
\begin{aligned}
& \text { _- Overall structure } \\
& \ldots-- \text { Core shear wall } \\
& \text {-.- Primary frame } \\
& \text {..... Outer tube }
\end{aligned}
$$

$$
\begin{aligned}
& \square \text { Yielding of coupling beams } \\
& \bigcirc \text { Yielding of braces } \\
& \triangle \text { Yielding of shear walls } \\
& \nabla \text { Yielding of primary column } \\
& \text { concrete }
\end{aligned}
$$

(b)

FIGURE 17: Stiffness degradation process of model 5MBC: (a) shear stiffness degradation; (b) bending stiffness degradation.

shear-stiffness degradation process can basically be divided into three stages. Stage 1, from the beginning to the displacement where the coupling beams yield, is the elastic stage in which the stiffness essentially remains constant. In the second stage, as the coupling beams yield, the structure enters the plastic stage, and the structural shear secant stiffness begins to decline. The shear secant stiffness of the core tube decreases rapidly once the coupling beams yield. The shear secant stiffness of the primary frame rapidly increases to a certain value and then remains essentially constant. In the third stage, once the braces yield, the core tube shear secant stiffness gently degrades. Conversely, the primary-frame secant stiffness begins to degenerate rapidly, then gradually stabilizes after the concrete yields in the primary-frame columns. The degradation process of the bending stiffness in $5 \mathrm{MBC}$ is similar to that of the shear stiffness. The exterior tube makes a greater contribution to structural overall bending stiffness. This shows that the exterior tube plays a major role in the bending resistance of the structural plastic development process.

Figure 18 shows that the stiffness degradation stage of the mega-X-braced frame-core tube structure, 5MXBC, is similar to that of the mega-diagonal-braced frame-core tube structure 5MBC. Compared with structural models 5MBC and $5 \mathrm{MXBC}$, the degeneration of the core wall stiffness weakens the lateral support of the exterior tube after the coupling beams yield in 5MC, as shown in Figure 19. The stiffness of the exterior tube degenerates significantly as the stiffness of the interior tube degenerates, which causes the overall structural stiffness to degenerate sharply. The shearstiffness degradation process of $5 \mathrm{MC}$ can be divided into two stages instead of three stages, because the stage wherein the interior tube degrades and the external tube does not degrade does not occur. Figure 20 compares the rate of degradation of overall structural stiffness. The stiffness of the frame-core tube structure without braces degrades rapidly after the coupling beams yield, whereas the stiffness of the frame-core tube structure with mega braces degrades rapidly after the braces yield. That is, the mega braces provide unremitting stiffness in the nonlinear development process and reduce the rate at which the structural stiffness degrades. The exterior tube contributes significantly to structural overall bending stiffness, regardless of whether there are mega braces (Figures 17-19).

The factors that influence the structural secant stiffness are analyzed in Figure 21. The factors that affect the megabraced frame-core tube structure do not affect the degradation and evolution of the structural secant stiffness. Strengthening the shear walls and coupling beams can increase the stiffness of the interior tube, which is more obvious before the braces yield. Strengthening the primary columns and braces can significantly increase the stiffness of the exterior tube, while exerting less effect on the interior tube. Reinforcing the shear walls can reduce the secant stiffness of the exterior tube because the interior tube has a larger stiffness and distributes more internal forces. The influence of component parameters on the stiffness of the interior and exterior tubes is relatively limited. That is, the enhancement of the exterior-tube members only increases the stiffness of the exterior tube, whereas the enhancement of the interior-tube members only enhances the stiffness of the interior tube. The overall degradation of the structural stiffness in the plastic stage is the result of degradation in the secant stiffness of the core walls, which is mainly caused by the yielding of the coupling beams. With the primary frame entering the plastic stage, the synchronous degradation of the core walls and the primary-frame secant stiffness further reduce the overall structural lateral stiffness.

\section{Behavior Factors of Structures}

Figure 22 shows the base shear versus roof displacement for the three model structures, as established using the 


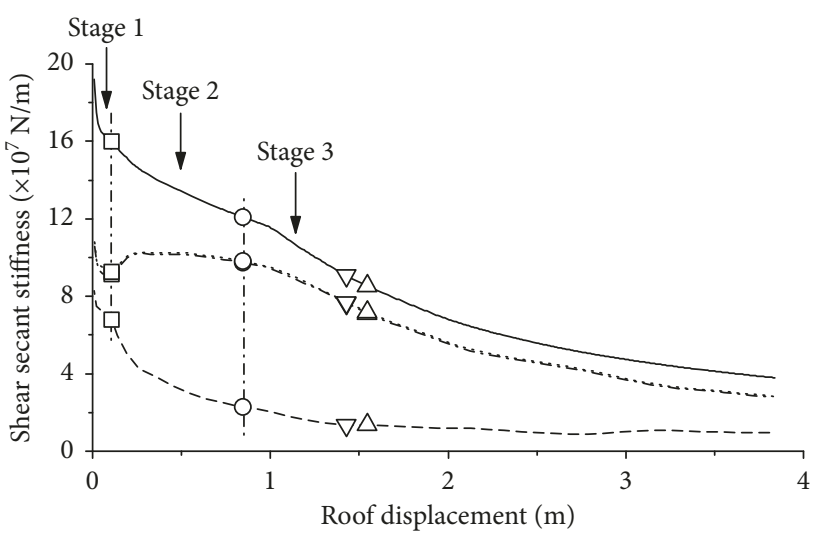

$\begin{array}{ll}\text { - Overall structure } & \square \text { Yielding of coupling beams } \\ \text {--- Core shear wall } & \bigcirc \text { Yielding of braces } \\ \text {-.- Primary frame } & \triangle \text { Yielding of shear walls } \\ \text {.... Outer tube } & \nabla \text { Yielding of primary column } \\ & \text { concrete }\end{array}$

(a)
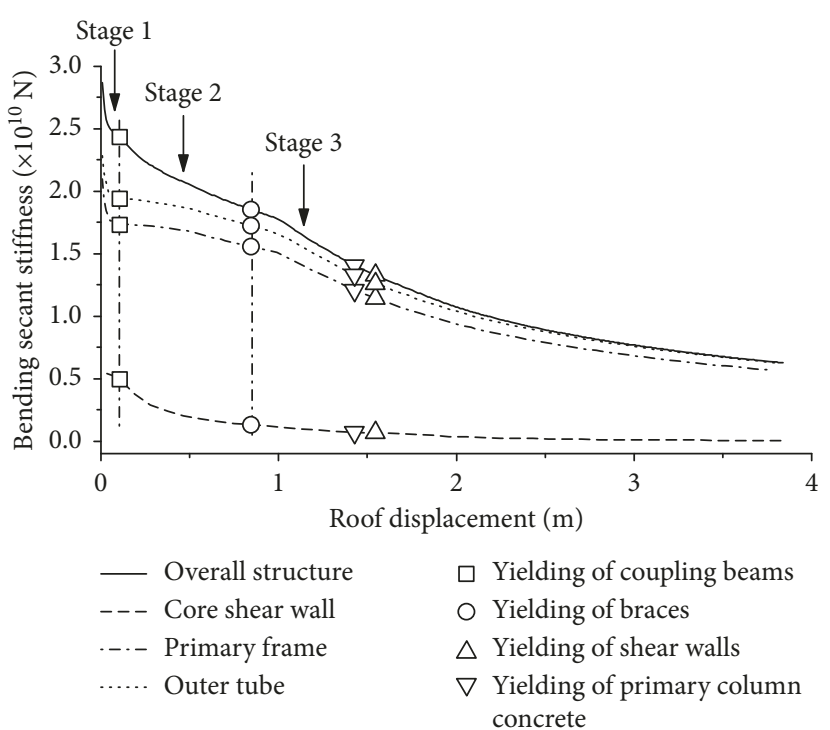

(b)

FIGURE 18: Stiffness degradation process of model 5MXBC: (a) shear stiffness degradation; (b) bending stiffness degradation.

nonlinear static pushover method. According to the definition, the ductility factor $\mu$ and overstrength factor $R_{\mathrm{o}}$ are defined as follows: [34].

$$
\begin{array}{r}
R_{\mathrm{o}}=\frac{V_{\mathrm{y}}}{V_{\mathrm{d}}}, \\
\mu=\frac{\Delta_{\max }}{\Delta_{\mathrm{y}}},
\end{array}
$$

where $V_{\mathrm{d}}$ is the design base shear, $V_{\mathrm{y}}$ is the base shear at the structural yield point, and $\Delta_{\max }$ is maximum roof story displacement of the structure, $\Delta_{\mathrm{y}}$ is the displacement at the structural yield point. The ductility factor $\mu$ is obtained from the system ductility ratio using the procedure proposed by Newmark and Hall [35].

The pushover curves shown in Figure 5 were used to evaluate the overstrength factors and ductility factors. To calculate the behavior factor, we consider a maximum drift of 0.02 as the collapse-prevention limit state [36]. Figure 23(a) shows the ductility factors for the three structure models; note that structural ductility decreases as the braces strengthen. The strengthening of braces limits the plastic development zone of the secondary structure. This reduces the number of structure components entering into plasticity before structural failure, resulting in the reduction of structural overall ductility. The increase in the axial force of the primary columns reduces their ductility, which leads to an earlier failure of the primary column. The primary column is a key component in the nonlinear development process of the structure. The premature failure of the primary column accelerates the failure of the overall structure, significantly reduces the ductility of the structure. Figure 23(b) plots the overstrength factors of the three structure models in different seismic fortification intensity according to Chinese Code. The structural overstrength of
$5 \mathrm{MC}, 5 \mathrm{MBC}$, and 5MXBC are 1.5 5.9, 2.6 10.2, 3.3 13.1, respectively. With the increase of seismic fortification intensity, the base shear force increases and the structural overstrength decreases. In the same seismic fortification intensity, the structural overstrength increases with the strengthening of the braces. It can be seen from this, strengthening the braces not only improves the stiffness of the exterior tube, but also increases its carrying capacity. The brace in exterior can take on the internal force transmitted from the interior tube and mitigate the rate of degradation of the system stiffness during its nonlinear development process (Figure 20). The exterior tube with mega braces improves its function as a second line of seismic defence and improves the overstrength of the structural system.

\section{Nonlinear Dynamic Analysis: Results and Discussion}

The literature shows that nonlinear static analysis cannot fully describe the dynamic behavior of high-rise buildings with a significant participation of higher-order modes [9]. This section analyzes the nonlinear incremental dynamics [37] by applying the three normalized earthquake records shown in Figure 24: the El Centro earthquake (NS), the Imperial Valley earthquake, and artificial ground acceleration. The response spectrum values of artificial ground acceleration are matched with Chinese seismic codes.

Figure 25 compares the maximum base shear of the three model structures for different seismic-intensity inputs (from $100 \mathrm{~cm} / \mathrm{s}^{2}$ to $1400 \mathrm{~cm} / \mathrm{s}^{2}$ ). The figure shows the first yielding points of the main components for corresponding seismic-intensity inputs. The base shear and yielding point are the average results analyzed by three earthquake records. 


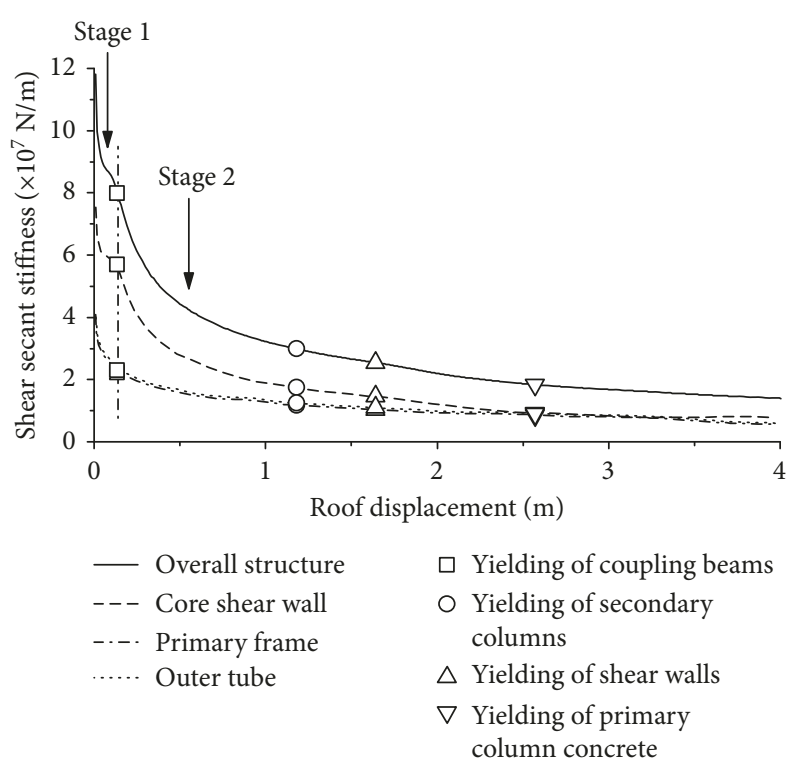

(a)

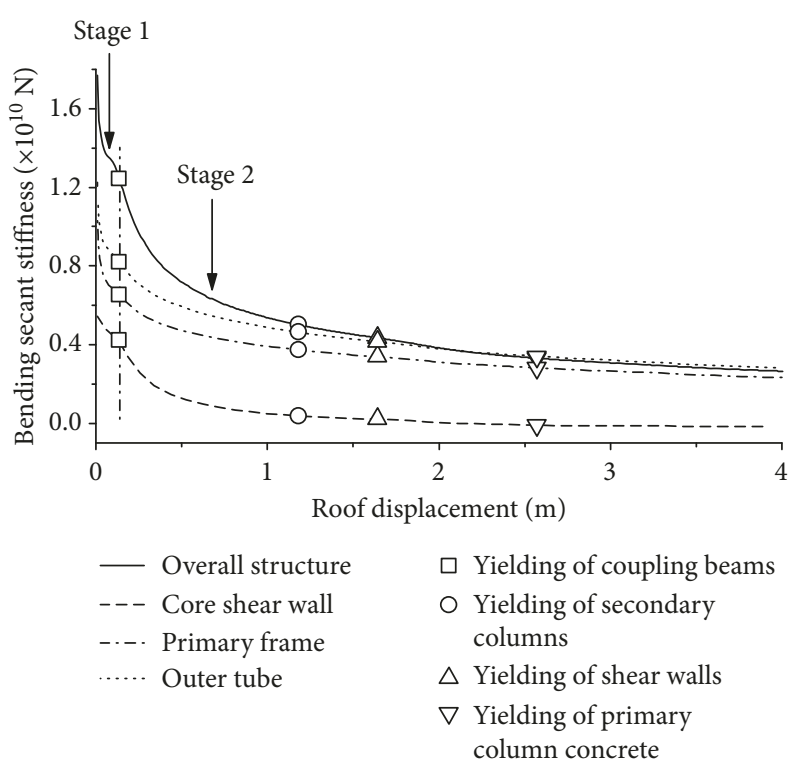

(b)

FIGURE 19: Stiffness degradation process of model 5MC: (a) shear stiffness degradation; (b) bending stiffness degradation.

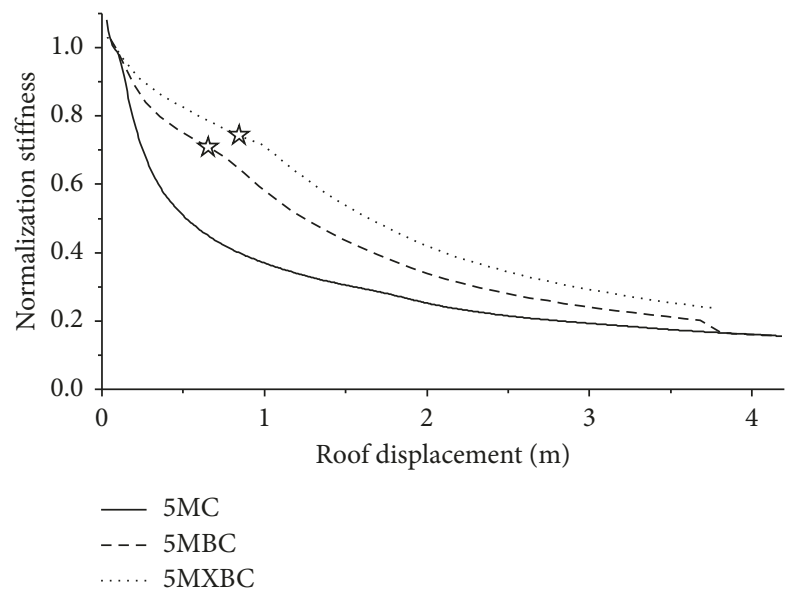

Figure 20: The normalization stiffness curves of three model structure.

For the three model structures, the maximum base shear force obtained from the incremental dynamic analysis [37] is similar to that from the pushover analysis. The stiffness and shear force of 5MC, 5MBC, and 5MXBC increases in turn under the same seismic-intensity inputs. The yield order of components under seismic action is basically the same as that obtained from the pushover analysis. This means that the pushover analysis properly predicts the behavior of megabraced frame-core tube structures under seismic action. Under the seismic action, it is worth noting that the yield moment of the primary beams tends to be postponed, and the yield moment of primary columns tends to be advanced.

The structural plastic distribution process of the exterior tube under seismic action differs slightly from that obtained by pushover analysis. The trends of the structural plastic distribution process of the exterior tube are consistent under different seismic wave inputs and different bracing arrangements. Thus, we take as an example the failure process of model 5MBC under the El Centro (NS) earthquake input (Figure 26).

Figure 26(a) shows that the diagonal braces in the bottom-two modules yield almost synchronously under seismic action. The secondary beams of the exterior tube begin to develop plasticity from the junction region between the first and second modules. The plastic region analyzed by the increment dynamic analysis (IDA) method is lower than that obtained by the pushover method. The plastic hinges spread from the junction region of the first and second modules up and down to other components. This is similar to that of the failure obtained by the pushover analysis. However, due to the significant participation of higher-order modes, the braces for the high stories enter the plastic regime earlier than suggested by the 


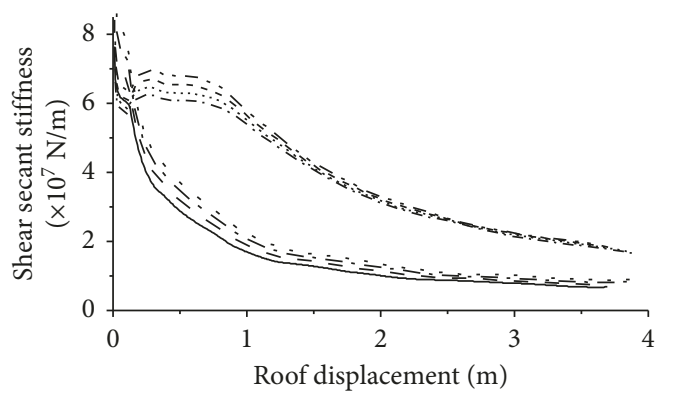

_ Core tube with parameters changing to 0.8 times

- - - Core tube with parameters no changing

-...- Core tube with parameters changing to 1.2 times

..... Core tube with parameters changing to 1.4 times

. - ... Primary frame with parameters changing to 0.8 times

- - - Primary frame with parameters no changing

....... Primary frame with parameters changing to 1.2 times

-...- Primary frame with parameters changing to 1.4 times

(a)

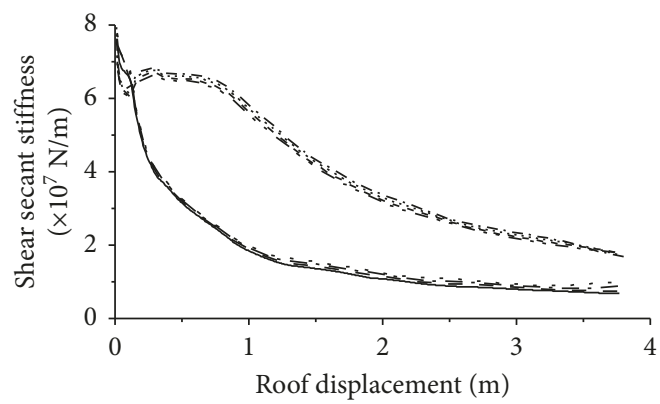

- Core tube with parameters changing to 0.8 times

- - - Core tube with parameters no changing

-...- Core tube with parameters changing to 1.2 times

Core tube with parameters changing to 1.4 times

. - .. Primary frame with parameters changing to 0.8 times

- - - Primary frame with parameters no changing

Primary frame with parameters changing to 1.2 times

-...- Primary frame with parameters changing to 1.4 times

(c)

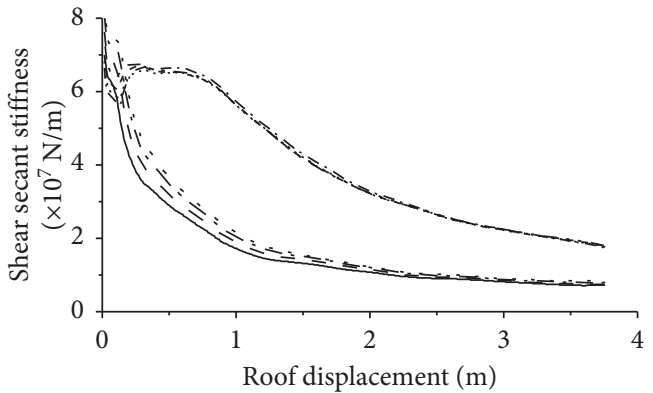

- Core tube with parameters changing to 0.8 times

- - - Core tube with parameters no changing

-...- Core tube with parameters changing to 1.2 times

.... Core tube with parameters changing to 1.4 times

. - ... Primary frame with parameters changing to 0.8 times

- - - Primary frame with parameters no changing

....... Primary frame with parameters changing to 1.2 times

.... Primary frame with parameters changing to 1.4 times

(b)

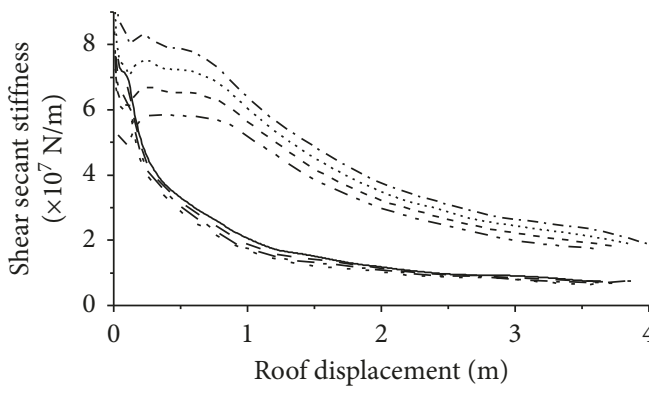

_ Core tube with parameters changing to 0.8 times

- - - Core tube with parameters no changing

-...- Core tube with parameters changing to 1.2 times

. Core tube with parameters changing to 1.4 times

- -.. Primary frame with parameters changing to 0.8 times

- - - Primary frame with parameters no changing

...... Primary frame with parameters changing to 1.2 times

.... Primary frame with parameters changing to 1.4 times

(d)

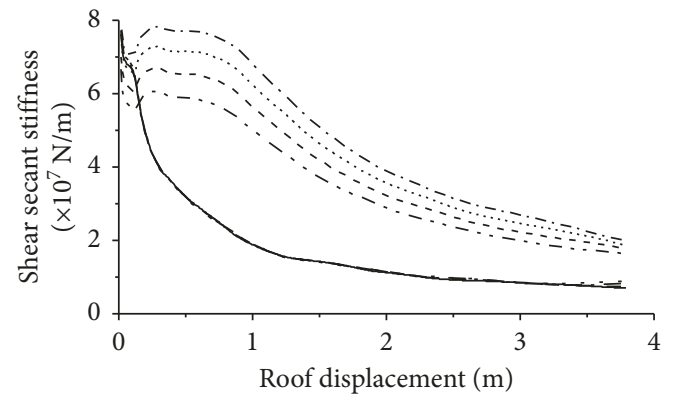

_ Core tube with parameters changing to 0.8 times

- - - Core tube with parameters no changing

-...- Core tube with parameters changing to 1.2 times

..... Core tube with parameters changing to 1.4 times

. - .. Primary frame with parameters changing to 0.8 times

- - - Primary frame with parameters no changing

....... Primary frame with parameters changing to 1.2 times

-... Primary frame with parameters changing to 1.4 times

(e)

FIGURE 21: Influence of key parameters on shear secant stiffness degradation of primary frame in model 5MBC: (a) thickness of shear walls, (b) height of coupling beams, (c) height of primary beams, (d) sectional area of primary columns, (e) sectional area of braces. 


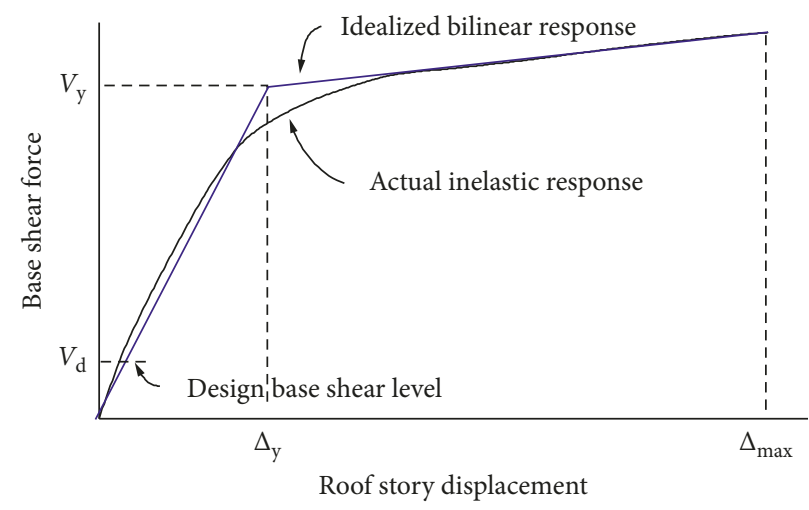

Figure 22: Idealized base shear-roof displacement relationship of a structure.

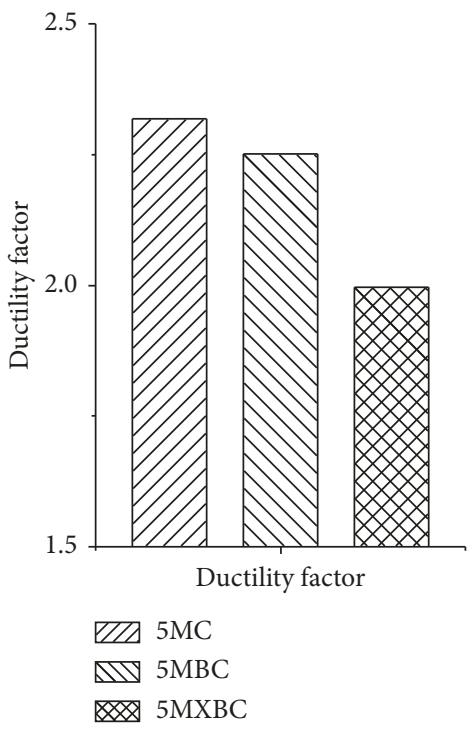

(a)

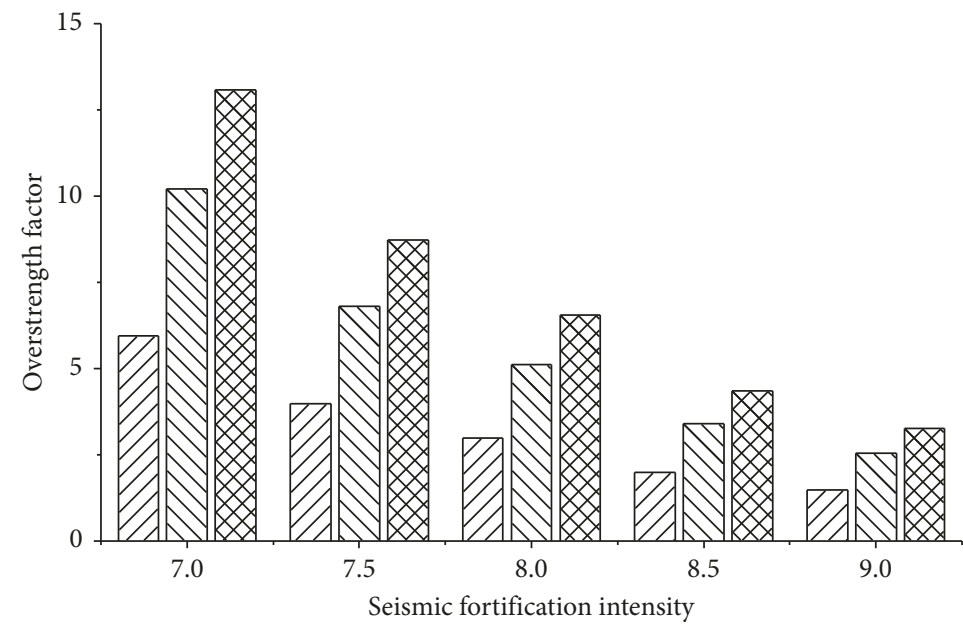

EII 5MC

NII $5 \mathrm{MBC}$

5MXBC

(b)

FIGURE 23: Behavior factors of the model structure: (a) ductility factors; (b) overstrength factors.

pushover analysis [38], as shown in Figure 26(b). The yielding region of the entire structure is lower, and the yielding components in the bottom of the structure are more than those indicated by the pushover analysis. This leads to premature degradation of the stiffness of the bottom structure, facilitating the entry of the primary columns into the plastic stage. In the same way, the yielding of the secondary frame beams develops with the plasticity of the braces during the development of structural plasticity.

The IDA method and pushover method give the same result in yield order and characteristics of plasticity. These results also indicate that a slight distinction exists between the results of the nonlinear static analysis and the dynamic analysis of the megabraced frame-core tube structure. The yielding region is lower, and the primary column in the bottom structure more easily enters the plastic stage under seismic action. Ductility design of the primary column is particularly important under earthquake actions. It should prevent premature damage to the primary columns exposed to seismic action.

\section{Conclusions}

This work has focused on the seismic performance and failure mechanism of megabraced frame-core tube structures with three different brace patterns. The yield order of components, distribution of plasticity, distribution of internal forces, degradation of structural nonlinear stiffness, and behavior factor were analyzed by nonlinear static and dynamic analysis. The conclusions drawn from the numerical simulations can be summarized as follows:

(i) The yielding of mega braces in megabraced framecore tube structure will change the deformation mode of adjacent substructures, affecting the failure characteristics of the structure. The strengthening of mega braces reduces the plasticity region of 


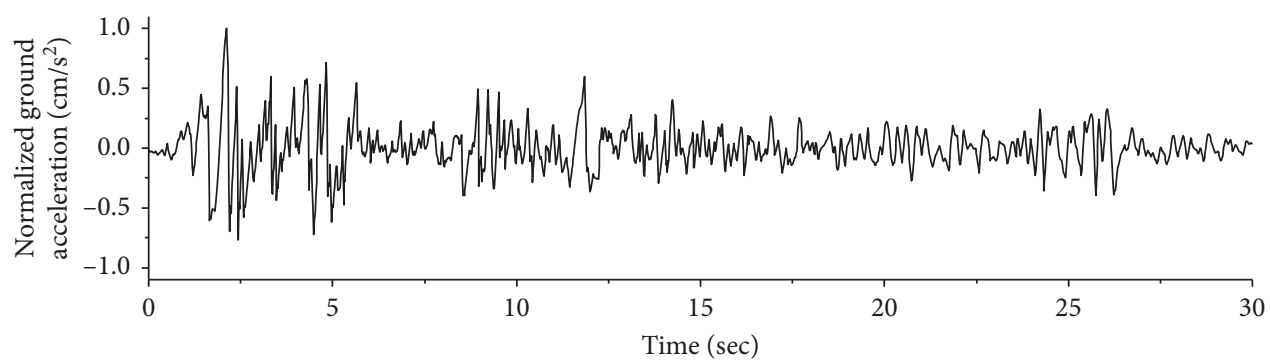

(a)

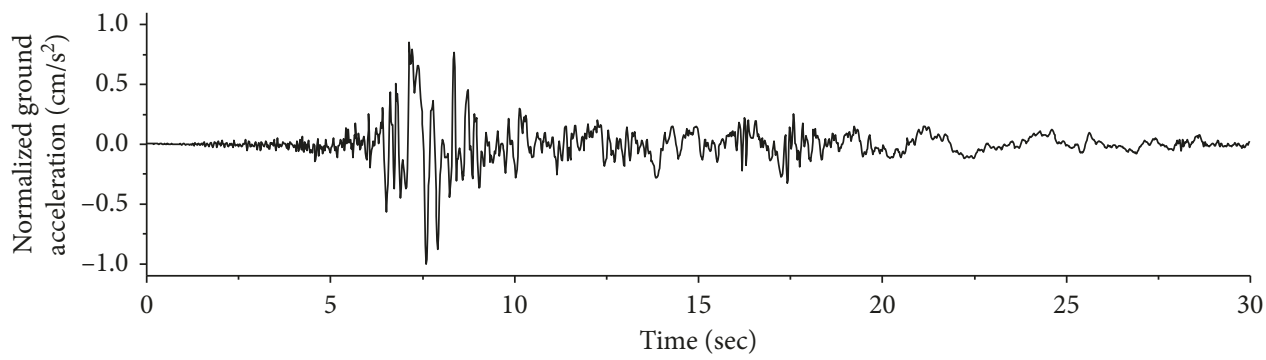

(b)

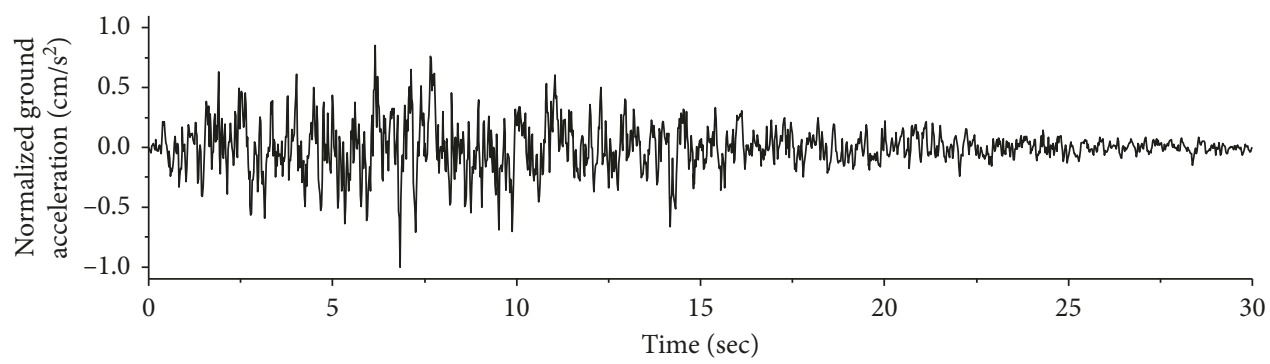

(c)

FIGURE 24: Earthquake records used in the incremental dynamic time-history analysis (a) El Centro earthquake NS components; (b) Imperial Valley record; (c) artificial ground acceleration.

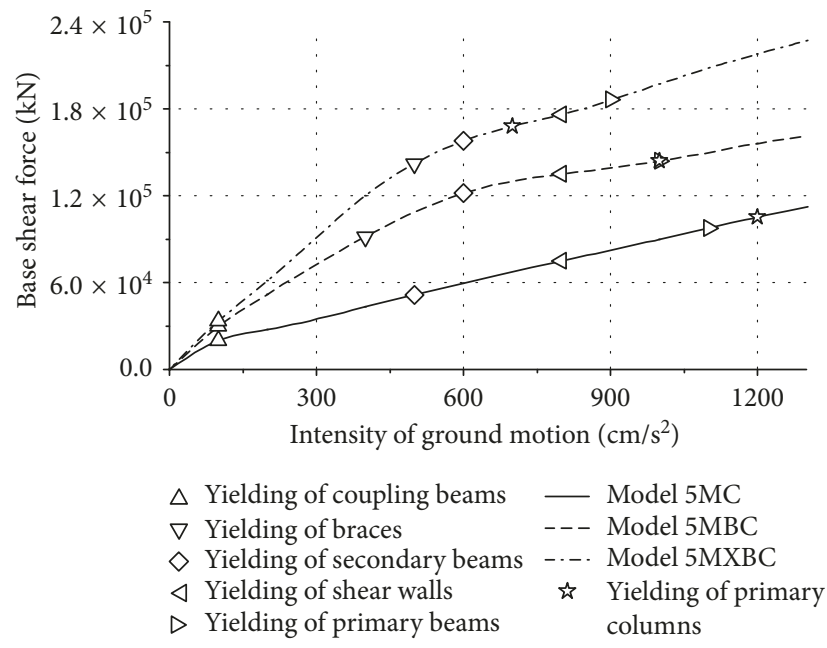

FIgURE 25: Component yielding order of three structure models under earthquake using IDA method.

substructures, indicating the reduction of structural ductility.

(ii) Megabraced frame-core tube structures with different brace patterns exhibit different internal force distribution characteristics. The enhancement of the mega braces improves the capacity of the external tubes to bear internal forces, increases the stiffness of the structure after the coupling beams yield, 


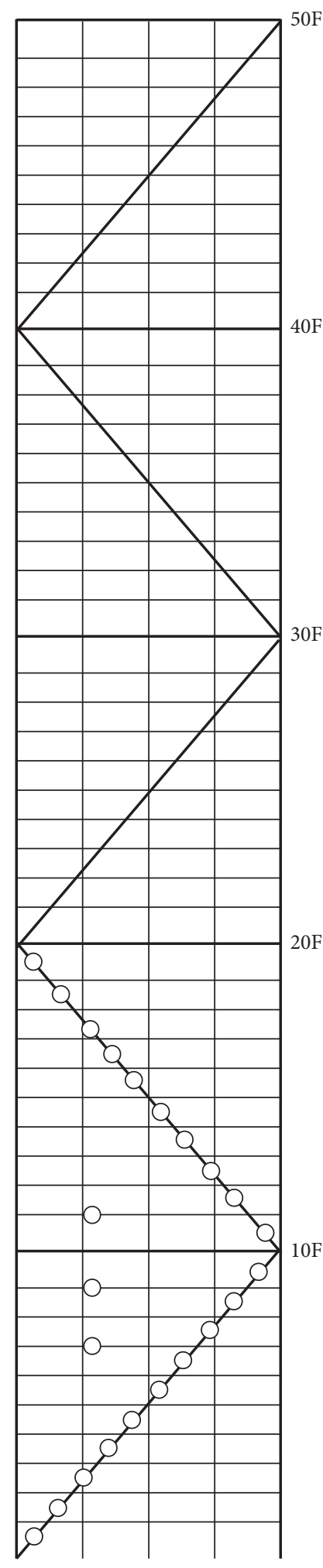

$\Delta_{\mathrm{y}}$

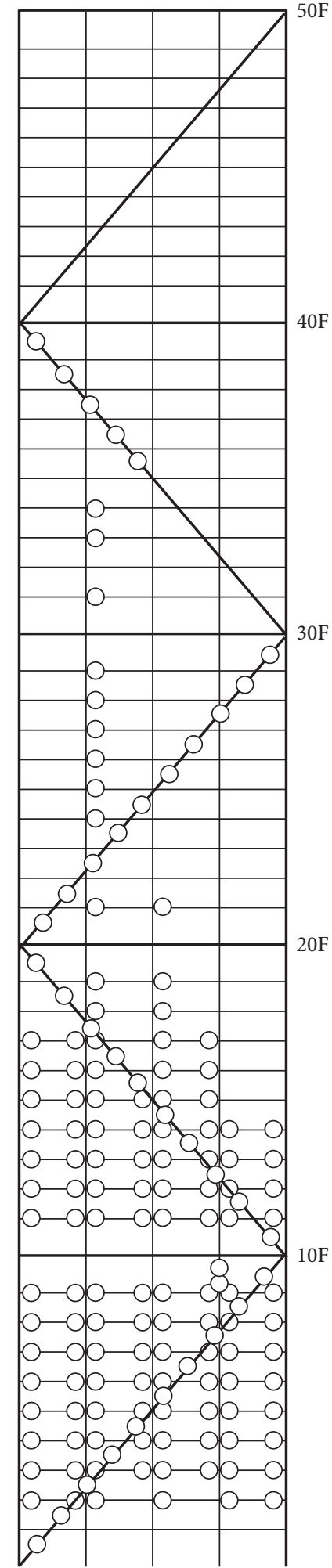

$\Delta_{\mathrm{y}}$

(a)

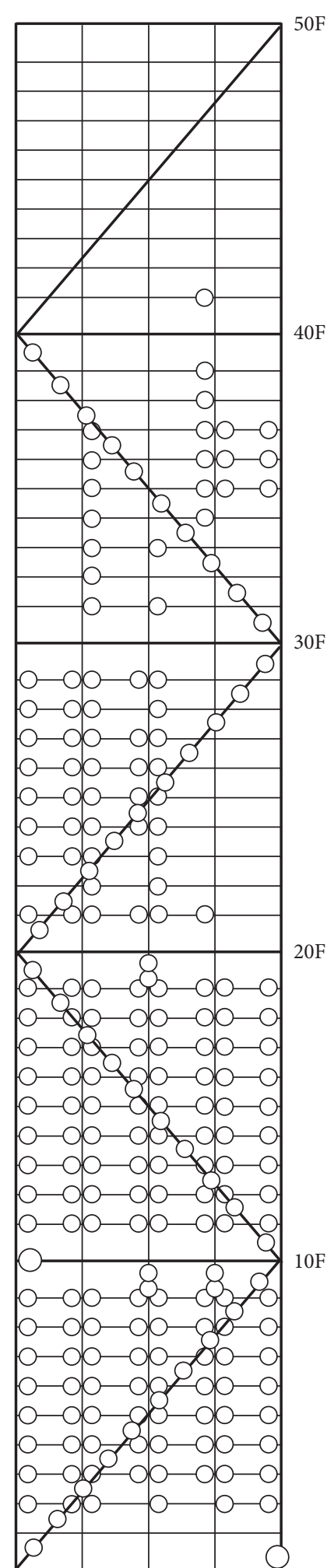

$\Delta_{\mathrm{y}}$

(c)

FIgUre 26: Plastic hinge formation in model 5MBC (web-side) by dynamic time-history analysis using El Centro earthquake input: (a) first yield; (b) secondary column; (c) primary beam and column. 
mitigates the rate at which the system stiffness degrades, and improves the overstrength of the structural system. These factors increase the capacity of mega braces to serve as the second line of seismic defence.

(iii) The yield order of components for megabraced frame-core tube structures has been studied. The enhancement of the braces leads to the earlier yielding of the primary columns. This reduces the ductility of the primary columns, further affecting the overall ductility of the structural system.

(iv) The nonlinear development process of megabraced frame-core tube structures subjected to earthquake action, mainly involving the yield order and the plasticity distribution of the components, is similar to the results obtained by the static pushover analysis.

\section{Data Availability}

The data used to support the findings of this study are included within the article.

\section{Conflicts of Interest}

The authors declare that they have no conflicts of interest.

\section{Acknowledgments}

This research is supported by the National Key Research and Development Program of China under grant no. 2016YFC0701102, the Major Program of National Natural Science Foundation of China under grant no. 51538003, China Major Development Project for Scientific Research Instrument under grant no. 51827811, and Shenzhen Technology Innovation Program under grant no. JCYJ20170811160003571.

\section{References}

[1] X. Lu, X. Lu, H. Guan, and L. Xie, "Application of earthquakeinduced collapse analysis in design optimization of a supertall building," Structural Design of Tall and Special Buildings, vol. 25, no. 17, pp. 926-946, 2016.

[2] X. Q. Yang, X. Y. Fu, and Y. J. Huang, "Dynamic elasto-plastic analysis of the shenzhen Ping'An financial center tower," Journal of Building Structures, vol. 7, pp. 40-49, 2011.

[3] L. Xilin, Z. Jiejiang, and Z. Yun, "Study on performance-based seismic design of shanghai world financial center tower," Journal of Earthquake and Tsunami, vol. 4, 2009.

[4] F. Z. Zhu, T. Y. Wang, X. S. Deng, and L. Chen, "Nonlinear seismic response analysis of a mega braced frame structure," World Earthquake Engineering, vol. 3, pp. 59-62, 2008.

[5] C. C. Pouangare and J. J. Connor, "New structural systems for tall buildings," Space-Truss Concept, vol. 4, no. 2, pp. 155-168, 1995.

[6] H. Yang, L. Chen, and Y. Zhou, "Analysis of performance of mega hybrid frame-corewall structure," Industrial Construction, vol. 3, pp. 63-67, 2011.

[7] L. Chen, H. Yang, and Y. Zhou, "Analysis on performance of mega SRC braced frame-core wall structure," Building Structure, vol. 3, pp. 91-95, 2012.
[8] X. Yu, T. Ji, and T. Zheng, "Relationships between internal forces, bracing patterns and lateral stiffnesses of a simple frame,” Engineering Structures, vol. 89, pp. 147-161, 2015.

[9] J. Kim, J. Park, S. Shin, and K. Min, "Seismic performance of tubular structures with buckling restrained braces," Structural Design of Tall and Special Buildings, vol. 18, no. 4, pp. 351-370, 2009.

[10] S. Qiao, X. Han, and K. Zhou, "Bracing configuration and seismic performance of reinforced concrete frame with brace," Structural Design of Tall and Special Buildings, vol. 26, no. 14, article e1381, 2017.

[11] D. M. Patil and K. K. Sangle, "Seismic behaviour of different bracing systems in high rise 2-D steel buildings," Structures, vol. 3, pp. 282-305, 2015.

[12] T. Jun, G. Weiliang, Z. Hao, and L. Zuohua, "Study of the nonlinear seismic performance of diagrid tube-core tube structures," China Civil Engineering Journal, vol. 8, pp. 90-96, 2012.

[13] D. M. Yu, L. Homing, and W. J. Lv, "Structural scheme selection for Wuhan CTF finance centre," Building Sturcture, vol. S2, pp. 6-11, 2017.

[14] T. Huang, X. Ren, and J. Li, "Incremental dynamic analysis of seismic collapse of super-tall building structures," Structural Design of Tall and Special Buildings, vol. 26, no. 16, article e1370, 2017.

[15] X. Lu, L. Xie, C. Yu, and X. Lu, "Development and application of a simplified model for the design of a super-tall megabraced frame-core tube building," Engineering Structures, vol. 110, pp. 116-126, 2016.

[16] K. M. Heiza and M. A. Tayel, "Comparative study of the effects of wind and earthquake loads on," High-Rise Buildings, vol. 3, pp. 386-404, 2012.

[17] H. Xiaojian and G. Ming, "Comparison between wind and earthquake loadings on tall buildings in shanghai in accordance with building structure codes," Journal of Tongji University (Natural Science), vol. 10, pp. 15-20, 2005.

[18] GB 50011-2010, Code for Seismic Design of Buildings, China Architecture and Building Press, Beijing, China, 2010.

[19] L. Bao, D. Wang, J. Zhou, and J. Chen, "Design and rethinking of mega brace in Tianjin 117 tower," Progress in Steel Building Structures, vol. 2, pp. 43-48, 2014.

[20] J. Kim and H. Choi, "Behavior and design of structures with buckling-restrained braces," Engineering Structures, vol. 26, no. 6, pp. 693-706, 2004.

[21] H. Jiang, Y. Li, and J. Zhu, "Numerical simulation of mega steel reinforced concrete columns with different steel sections," Structural Design of Tall and Special Buildings, vol. 26, no. 1, article e1304, 2017.

[22] H. Zhao, Q. Lei, S. Hou, and H. Lin, "Engineering application of 8 columns mega frame-core wall system in Guangzhou East tower,” Building Structure, vol. 10, pp. 1-6, 2012.

[23] R. Montuori and V. Piluso, "Analysis and modelling of CFT members: moment curvature analysis," Thin-Walled Structures, vol. 86, pp. 157-166, 2015.

[24] Y. Wu, J. Cai, C. Yang, Y. Zhou, and C. Zhang, "Mechanical behaviours and engineering application of steel truss reinforced concrete transfer beam in tall buildings," Structural Design of Tall and Special Buildings, vol. 20, no. 6, pp. 735-746, 2011.

[25] L. H. Han, "Tests on concrete filled steel tubular columns with high slenderness ratio," Advances in Structural Engineering, vol. 3, no. 4, pp. 337-344, 2000.

[26] J. B. Mander, M. J. N. Priestley, and R. Park, "Theoretical stress-strain model for confined concrete," Journal of Structure Engineering, vol. 114, no. 8, pp. 1804-1826, 1988. 
[27] C. Xuewei, H. Xiaolei, L. Fan, and W. Shuang, "Fiber element based elastic-plastic analysis procedure and engineering application," Procedia Engineering, vol. 14, pp. 1807-1815, 2011.

[28] M. N. Aydinoğlu, "An incremental response spectrum analysis procedure based on inelastic spectral displacements for multi-mode seismic performance evaluation," Bulletin of Earthquake Engineering, vol. 1, pp. 3-36, 2003.

[29] R. Montuori and R. Muscati, "Smart and simple design of seismic resistant reinforced concrete frame," Composites Part B: Engineering, vol. 115, pp. 360-368, 2017.

[30] H. Hu, C. Huang, M. Wu, and Y. Wu, "Nonlinear analysis of axially loaded concrete-filled tube columns with confinement effect," Journal of Structural Engineering, vol. 129, no. 10, pp. 1322-1329, 2003.

[31] Z. B. Wang, Z. Tao, L. H. Han, B. Uy, D. Lam, and W. H. Kang, "Stiffness and ductility of concrete-filled steel columns under axial compression," Engineering Structures, vol. 135, pp. 209-221, 2017.

[32] S. Costanzo, M. D'Aniello, and R. Landolfo, "Seismic design criteria for chevron CBFs: proposals for the next EC8 (part2)," Journal of Constructional Steel Research, vol. 138, pp. 17-37, 2017.

[33] G. Weiliang, T. Jun, R. Baisheng, and L. Zuohua, "A seismic behaviour of a diagrid tube-core structure," Journal of Vibration and Shock, vol. 4, pp. 150-155, 2011.

[34] J. Osteraas, Strength and Ductility Considerations in Seismic Design, Stanford University, Stabford, CA, USA, 1990.

[35] N. M. Newmark and W. J. Hall, "Earth system dynamics," in Earthquake Spectra and Design, Earthquake Engineering Research Institute, Oakland, CA, USA, 1982.

[36] BSSC, NEHRP Recommended Provisions for Seismic Regulations for New Buildings and Other Structures. Part 1: Provisions, FEMA-450, BSSC, Washington, DC, USA, 2004.

[37] D. Vamvatsikos, "Incremental dynamic analysis," Earthquake Engineering and Structural Dynamics, vol. 3, pp. 491-514, 2015.

[38] S. Hou and J. P. Ou, "A study of load pattern selection of pushover analysis and influence of higher modes," Earthquake Engineering and Engineering Vibration, vol. 3, pp. 89-97, 2004. 


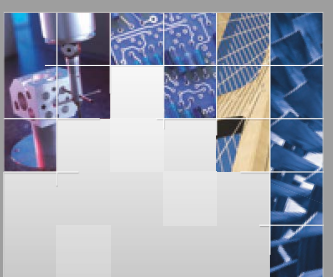

\section{Enfincering}
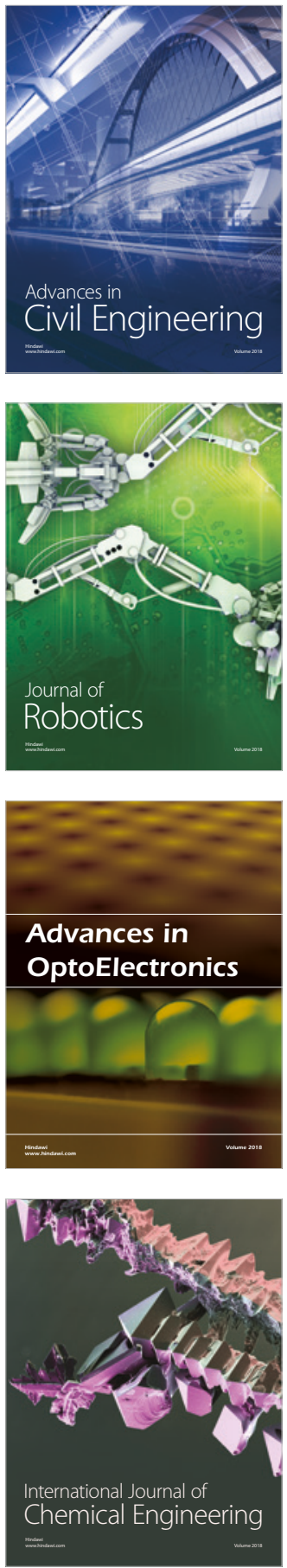

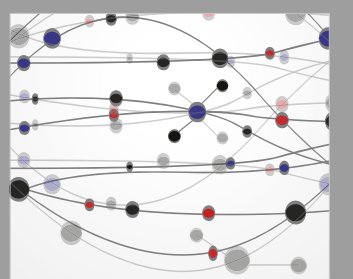

\section{Rotating \\ Machinery}

The Scientific World Journal

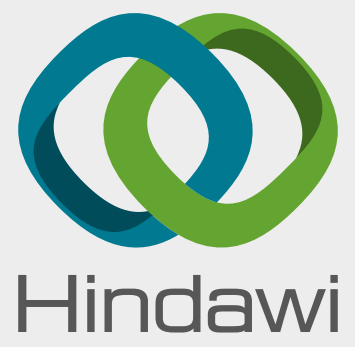

Submit your manuscripts at

www.hindawi.com
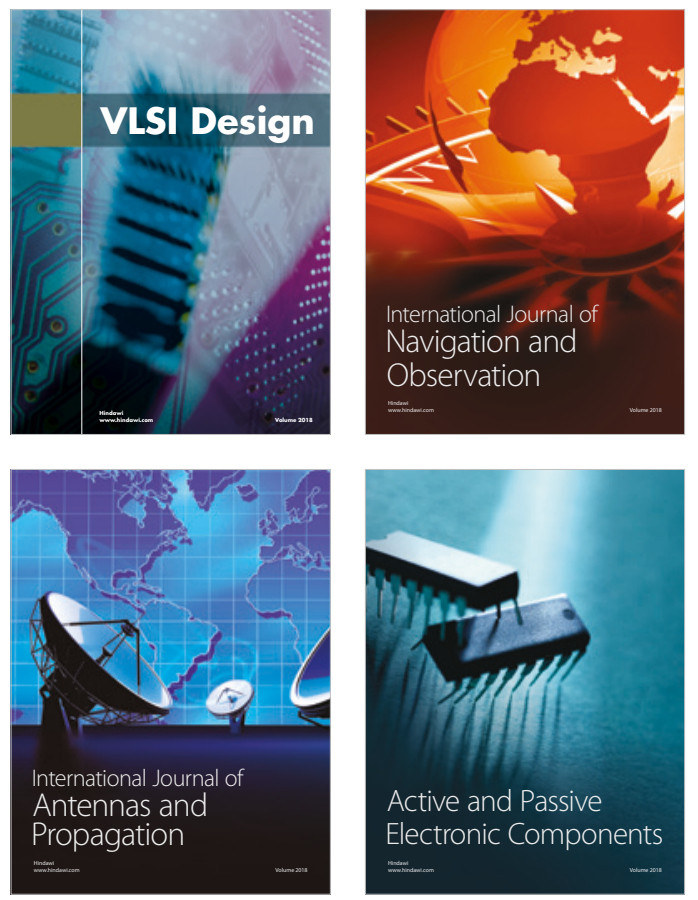
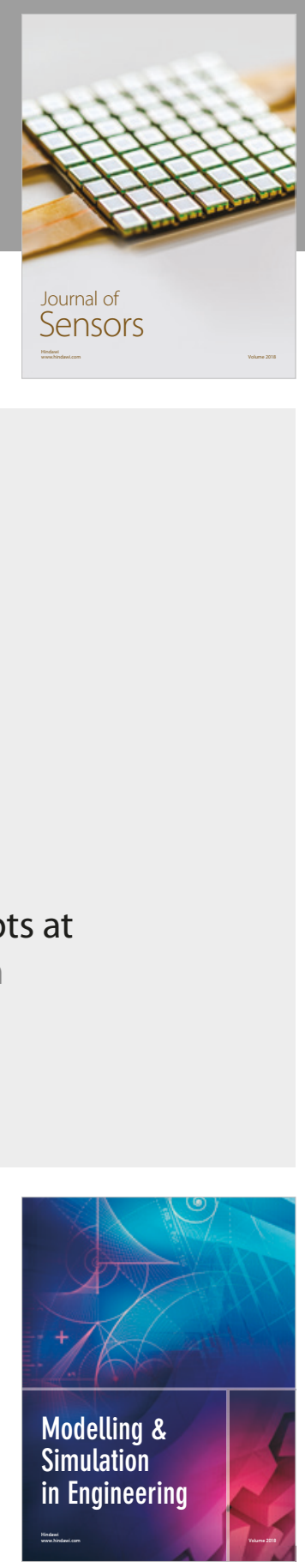

\section{Advances \\ Multimedia}
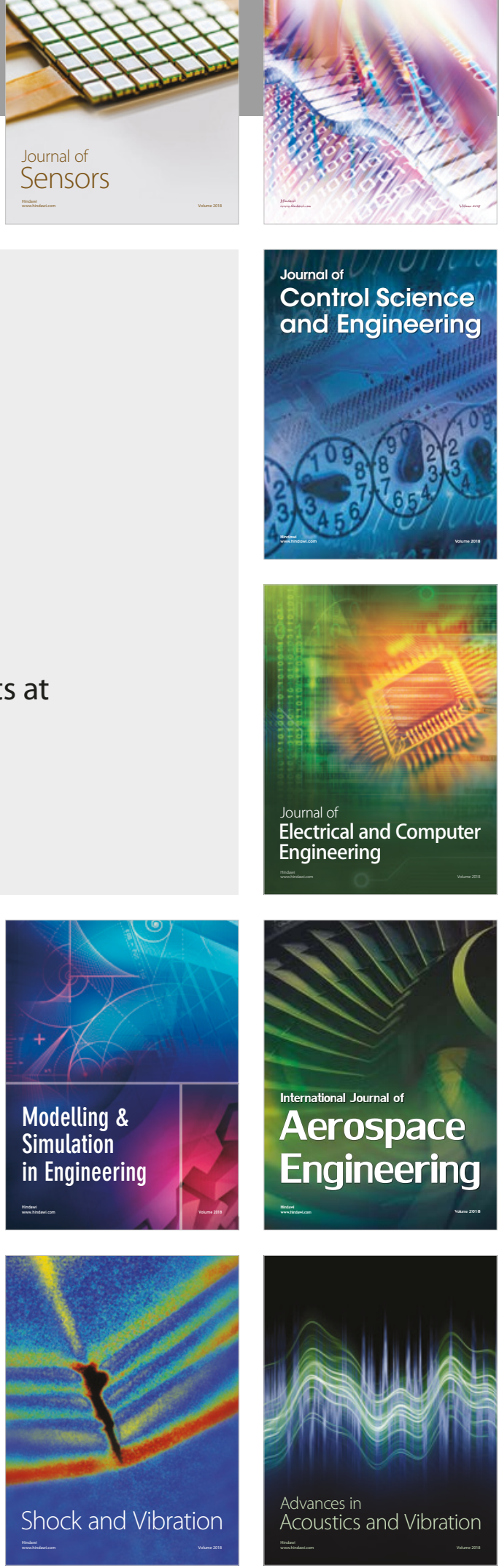